\title{
New EDM Generator Used for the Machining of 1.2363 and 1.2343ESR Steels
}

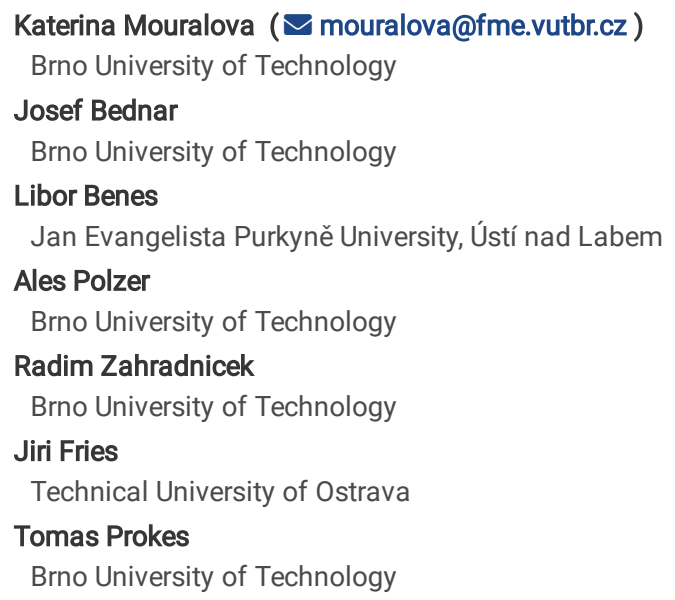

Research Article

Keywords: die- sinking EDM, generator, steel, design of experiment, cracks, machining parameters

Posted Date: December 9th, 2021

DOI: https://doi.org/10.21203/rs.3.rs-1119379/v1

License: (c) (i) This work is licensed under a Creative Commons Attribution 4.0 International License. Read Full License 


\section{Abstract}

The basic building block of any electric discharge machine is a generator, which ensures the operation of material separation itself. Not only the erosion rate and electricity consumption but also the quality of the machined surfaces depend on the design of the generator. These key factors for efficient machining have been investigated using a new energy-saving and powerful generator developed for the electric discharge machine (EDM) while machining 1.2363 and 1.2343ESR steels. In order to monitor and model the responses in the form of eroding rate and surface quality, a two-level half-factor experiment was performed with one replication at the corner points and two replications at the central points, for a total of 80 rounds. Both graphite and copper electrodes of sizes 10x10 mm and 100x100 mm were used for eroding and the influence of parameter settings: Open-voltage, Pulse current, Pulse on-time and Pulse offtime was monitored. It was found out that the shape of the electrode and Pulse current have the most significant effect on the erosion rate. The parameters Pulse current, Pulse on-time and their mutual interaction have the most significant effect on the surface topography. Statistically significant factors influencing the occurrence of defects turned out to be Pulse current, Pulse on-time and Material of workpiece, where it can be seen that the material 1.2343ESR is significantly less prone to the formation of surface defects.

\section{Introduction}

Electrical discharge machining (EDM) is one of the unconventional machining technologies, where the material is removed thanks to the thermoelectric process, which takes place between the workpiece and the tool electrode in the working medium - dielectric fluid. The basic building block of the EDM machine is the generator, which affects not only the erosion rate but also the quality of the machined surface and electrode wear. This generator of electric discharges must therefore combine several requirements at the same time. Especially at a time when there is great pressure on the competitiveness and efficiency of technological processes [1, 2].

The basic advantage of electrical discharge machining is that no classical mechanical forces affect the workpiece and it is not deformed in any way by them. Erosion takes place on all at least minimally electrically conductive materials, so it is not necessary to take into account the mechanical properties of the material being machined, such as toughness or high hardness. It is therefore possible to machine materials after the final heat treatment, when their size will no longer be affected by anything [3].

The disadvantage of this unconventional machining technology lies in its relatively high energy consumption, therefore it is necessary to achieve the highest possible erosion rate, but with the creation of the required surface quality of the machined part. Another disadvantage can happen to be the relatively complex production of complicated shaped electrodes, which always form the negative shape of the final workpiece [4].

Lee [6] tried to optimize the machining characteristics, namely the surface roughness and tool wear rate, for the achievement of which the employed the utility concept and Multi characteristic Optimization. A range of experiments was performed where various combinations of input parameters were utilized, and it was found out that current was the most significant factor for the optimization of the machining characteristics under investigation, followed by duty cycle and voltage, and pulse on time appeared to be the least significant. Straka [7] studied the optimization of the tool wear rate and material removal rate of $\mathrm{Cu}$ electrode during the die-sinking EDM process. Several process parameters were chosen and their influence on the machining characteristics was observed. The optimization of these parameters was achieved in the course of experiments. Purohit [8] focused on the EDM process of the tool steels and tried to optimize the output parameters, namely electrode wear ratio, metal removal rate and over cut taking into account several input parameters, such as spar and voltage time and tool rotation speed. During the range of the experiments a rotary brass electrode was employed for the electric discharge machining. Grey relational analysis and the analysis of variance were used to perform the machining of the material under the investigation. Molinetti [9] aimed at the evaluation of hardness, the chemical composition, surface roughness and the micro-structure of the recast layer during the EDM process, which were influenced by silicon and manganese powders with fine particle sizes. Scanning electron microscopy, X-ray diffraction and energy dispersive spectroscopy techniques were employed in the experiments. It was found out that the best results were obtained while using the silicon powder with respect to the surface quality. Prasad [10] focused on the research of the machining parameters during the EDM process of the tool steel. Copper electrode was employed for the machining, and the minimum surface integrity and maximum material removal rate of the surface were investigated during the EDM process. For all nine experiments performed, the most important input parameters, such as pulse duration, pulse current, spark off time and discharge voltage were employed. As the result, the pulse current was proved to be the most influential parameter. Laxminarayana [11] studied the surface morphology of the machined surface during the die-sinking EDM process. A circular copper electrode was used for the experiment. The micro structure was evaluated by using the scanning electron microscopy, and the Taguchi method was used to define the optimum machining parameters for the EDM process. Świercz [12] investigated the properties of the surface layer of the tool steel with the high thermal conductivity after the EDM process. In the experiments performed the main influential machining parameters like pulse time and discharge current were studied. They also described the significant surface layer properties and established the effect of the response surface methodology of the parameters under investigation on them. Al-Khazraji [13] focused on the effect of powder mixing parameters of EDM using copper and graphite electrodes on the white layer thickness, the fatigue life and the total heat flux generated. Two groups of experiments were performed, just with the kerosene dielectric and then by adding the SiC micro powders mixing to dielectric fluid. Singh [14] studied the statistical and soft computer-based predictive models for the surface roughness (SR) and material removal rate (MRR) during the EDM process of die steel which was helium-assisted. They tried to develop mathematical models to predict the MRR and SR. The input process parameters, which were selected for the experiment, were pulse on time, discharge current, electrode rotation, duty cycle and discharge gas pressure.

Due to the increased energy intensity of EDM, it is necessary to understand in detail all the mechanisms affecting the erosion rate and the quality of the machined surface to ensure sustainable production with the highest possible efficiency. For this purpose, the following extensive study was carried out, which is unique not only in its scope, but also presents the latest knowledge gained using the new machine generator. This study builds on the knowledge gained during machining using an old generator presented in the Mouralova study [5]. As part of the design of experiment presented in this study, two steels 1.2363 
and 1.2343ESR were machined, which were chosen due to their wide range of applicability, especially in the production of plastic injection moulds. The outcomes of this study can be used to optimize the production of a range of components made of these two steels in real conditions of companies.

\section{Experimental Setup And Material \\ 2.1. Experimental material}

The samples for the experiment were made of two types of alloy steels, namely 1.2363 and 1.2343ESR. Mechanical properties, chemical composition and the use of both steels were compiled in Tab. 1. For the experiment, the starting semi-finished products were used always in the form of a plate with a thickness of $10 \mathrm{~mm}$, and they were divided for individual samples, which is shown in Fig. 1(d), the microstructure of the semi-finished products is shown by means of a light microscope (LM) in Fig. 1(e, f). The erosion depth of each sample was always $1 \mathrm{~mm}$.

Table 1

Mechanical properties at the room temperature and use of steels 1.2363 and $1.2343 E S R$

\begin{tabular}{|c|c|c|}
\hline \multicolumn{3}{|l|}{ Properties } \\
\hline Material & & Hardness \\
\hline 1.2363 & High dimensional stability, abrasion resistance, high toughness, good machinability & $241 \mathrm{HB}$ \\
\hline 1.2343ESR & $\begin{array}{l}\text { High hardenability and toughness, resistance to cracking, very good thermal conductivity, low sensitivity to rapid temperature } \\
\text { changes }\end{array}$ & $229 \mathrm{HB}$ \\
\hline \multicolumn{3}{|c|}{ Chemical Composition (wt\%): } \\
\hline 1.2363 & $5.15 \% \mathrm{Cr}, 0.6 \% \mathrm{Mn}, 1 \% \mathrm{C}, 1.05 \% \mathrm{Mo}, 0.25 \% \mathrm{Si}, 0.2 \% \mathrm{~V}$ and $\mathrm{Fe}-$ balance & \\
\hline 1.2343ESR & $5.3 \% \mathrm{Cr}, 0.4 \% \mathrm{Mn}, 0.38 \% \mathrm{C}, 1.2 \% \mathrm{Mo}, 1 \% \mathrm{Si}, 0.4 \% \mathrm{~V}$ and $\mathrm{Fe}-$ balance & \\
\hline \multicolumn{3}{|l|}{ Usage } \\
\hline 1.2363 & Compression and cutting tools, edging tools, longitudinal and circular shears, jaws for thread rolling, moulds for plastic injection ... & \\
\hline 1.2343ESR & Die casting moulds, forging and pressing dies, plastic injection moulds, plastics processing screws ... & \\
\hline
\end{tabular}

\subsection{EDM machine setup}

Graphite and pure copper tool electrodes (Fig. 1(b,c)) in two shapes were used for machining: 100x100 mm and 10x10 mm. All samples were made on a 433GS EDM machine supplied by the manufacturer PENTA and equipped with a new current modulating generator called P-MG2.The photographs of the erosion of the samples are shown in Fig. 1(a). The control is integrated into a field-programmable gate array (FPGA) with the possibility of later innovation, the input voltage is converted by a very fast A/D converter with a small delay. The generator is controlled via the EtherCAT fieldbus, which contains all control signals, feedback for axis control and diagnostics. Output current stages are variable (normally $0.2 \mathrm{~A} \sim 60 \mathrm{~A}$ ), pulse timing from $10 \mathrm{~ns}$ to 5 ms. A very important function is the multi-stage protection against inflammation and short circuit, especially for graphite electrodes and high current densities. During the machining, all samples were immersed in a dielectric liquid, which was kerosene.

In order to monitor the change in erosion rate and surface quality, which included changes in topography and the occurrence of defects, a design of experiment (DoE) was created. The design of experiment is a systematic change of process inputs to monitor and model the outputs of the process. In this experiment, 7 input factors were investigated, which are described in more detail in Tab. 2. 
Table 2

Inputfactorsof the experiment

\begin{tabular}{|lll|}
\hline Categorial & & \\
\hline Name & Designation & Unit \\
\hline Electrode shape & Shape & - \\
\hline Electrode material & Electrode & - \\
Workpiece material & Workpiece & - \\
\hline Numerical & & \\
\hline Open-voltage & $U$ & $\mathrm{~V}$ \\
\hline Pulse current & $I$ & $\mathrm{~A}$ \\
\hline Pulse on-time & Ton & $\mu \mathrm{s}$ \\
\hline Pulse off-time & Toff & $\mu \mathrm{s}$ \\
\hline
\end{tabular}

A half two-level factor design of experiment was created, where one replication was performed at the corner points and two replications were performed at the central points. The experiment includes $2^{7-1}=64$ runs (partial experiments) at corner points and $2^{3} \cdot 2=16$ runs at central points, as there is no central level for categorical factors and it is necessary to measure in all combinations of side levels of these categorical factors. The total number of runs was thus 80 , while the levels of input factors are shown in Tab. 3 and the input machining parameters for all 80 runs are in Tab. 4.

Table 3

Limit values of input parameters for the design of experiment.

\begin{tabular}{|c|c|c|c|c|c|c|c|}
\hline Parameter & Shape of electrode & Material of electrode & Material of workpiece & Open-voltage $(V)$ & Pulse current (A) & $\begin{array}{l}\text { Pulse on } \\
\text {-time }(\mu \mathrm{s})\end{array}$ & $\begin{array}{l}\text { Pulse off } \\
\text {-time ( } \mu s)\end{array}$ \\
\hline Lower level & $10 \times 10$ & copper & $\begin{array}{l}1.2363 \\
(1)\end{array}$ & 160 & 10 & 50 & 35 \\
\hline Centrallevel & & & & 220 & 20 & 125 & 92.5 \\
\hline Higher level & $100 \times 100$ & graphite & 1.2343ESR (2) & 280 & 30 & 200 & 150 \\
\hline
\end{tabular}

Tab.4 Machining input parameters used for individual runs of the experiment. 


\begin{tabular}{|c|c|c|c|c|c|c|c|c|c|c|c|c|}
\hline Samplenumber & $\begin{array}{l}\text { Shape of } \\
\text { electrode }\end{array}$ & $\begin{array}{l}\text { Material } \\
\text { of } \\
\text { electrode }\end{array}$ & $\begin{array}{l}\text { Material } \\
\text { of } \\
\text { workpiece }\end{array}$ & $\begin{array}{l}\text { Open- } \\
\text { voltage } \\
\text { (V) }\end{array}$ & $\begin{array}{l}\text { Pulse } \\
\text { current } \\
\text { (A) }\end{array}$ & $\begin{array}{l}\text { Pulse } \\
\text { on- } \\
\text { time } \\
(\mu s)\end{array}$ & $\begin{array}{l}\text { Pulse } \\
\text { off- } \\
\text { time } \\
(\mu s)\end{array}$ & $\begin{array}{l}\text { Sample } \\
\text { number }\end{array}$ & $\begin{array}{l}\text { Shape of } \\
\text { electrode }\end{array}$ & $\begin{array}{l}\text { Material } \\
\text { of } \\
\text { electrode }\end{array}$ & $\begin{array}{l}\text { Material } \\
\text { of } \\
\text { workpiece }\end{array}$ & $\begin{array}{l}\text { Open- } \\
\text { voltage } \\
\text { (V) }\end{array}$ \\
\hline 1 & $10 \times 10$ & graphite & 1 & 220 & 20 & 125 & 92.5 & 41 & $100 \times 100$ & graphite & 1 & 220 \\
\hline 2 & $100 \times 100$ & copper & 1 & 280 & 30 & 50 & 35 & 42 & $10 \times 10$ & copper & 1 & 280 \\
\hline 3 & $100 \times 100$ & graphite & 1 & 280 & 10 & 50 & 35 & 43 & $100 \times 100$ & graphite & 1 & 280 \\
\hline 4 & $10 \times 10$ & graphite & 2 & 280 & 30 & 200 & 35 & 44 & $100 \times 100$ & copper & 1 & 160 \\
\hline 5 & $100 \times 100$ & graphite & 1 & 280 & 30 & 200 & 35 & 45 & $100 \times 100$ & graphite & 2 & 160 \\
\hline 6 & $10 \times 10$ & graphite & 2 & 160 & 10 & 50 & 150 & 46 & $100 \times 100$ & copper & 2 & 160 \\
\hline 7 & $100 \times 100$ & copper & 1 & 160 & 30 & 50 & 150 & 47 & $100 \times 100$ & graphite & 2 & 280 \\
\hline 8 & $10 \times 10$ & graphite & 1 & 160 & 10 & 200 & 150 & 48 & $10 \times 10$ & graphite & 1 & 280 \\
\hline 9 & $10 \times 10$ & copper & 1 & 160 & 10 & 200 & 35 & 49 & $10 \times 10$ & copper & 2 & 220 \\
\hline 10 & $10 \times 10$ & copper & 1 & 220 & 20 & 125 & 92.5 & 50 & $100 \times 100$ & graphite & 2 & 160 \\
\hline 11 & $100 \times 100$ & copper & 2 & 280 & 30 & 50 & 150 & 51 & $100 \times 100$ & graphite & 2 & 280 \\
\hline 12 & $10 \times 10$ & copper & 1 & 220 & 20 & 125 & 92.5 & 52 & $100 \times 100$ & graphite & 1 & 160 \\
\hline 13 & $10 \times 10$ & graphite & 2 & 160 & 30 & 50 & 35 & 53 & $10 \times 10$ & copper & 1 & 280 \\
\hline 14 & $100 \times 100$ & copper & 1 & 220 & 20 & 125 & 92.5 & 54 & $10 \times 10$ & graphite & 1 & 280 \\
\hline 15 & $10 \times 10$ & copper & 2 & 280 & 30 & 200 & 150 & 55 & $100 \times 100$ & graphite & 1 & 160 \\
\hline 16 & $100 \times 100$ & graphite & 2 & 220 & 20 & 125 & 92.5 & 56 & $10 \times 10$ & graphite & 2 & 280 \\
\hline 17 & $10 \times 10$ & copper & 1 & 160 & 30 & 200 & 150 & 57 & $10 \times 10$ & graphite & 2 & 160 \\
\hline 18 & $10 \times 10$ & copper & 1 & 280 & 10 & 50 & 35 & 58 & $100 \times 100$ & graphite & 2 & 280 \\
\hline 19 & $10 \times 10$ & copper & 2 & 280 & 10 & 50 & 150 & 59 & $100 \times 100$ & graphite & 1 & 160 \\
\hline 20 & $100 \times 100$ & copper & 2 & 220 & 20 & 125 & 92.5 & 60 & $100 \times 100$ & copper & 1 & 280 \\
\hline 21 & $100 \times 100$ & graphite & 1 & 220 & 20 & 125 & 92.5 & 61 & $100 \times 100$ & graphite & 1 & 280 \\
\hline 22 & $10 \times 10$ & copper & 2 & 160 & 10 & 200 & 150 & 62 & $100 \times 100$ & copper & 1 & 280 \\
\hline 23 & $10 \times 10$ & graphite & 2 & 160 & 30 & 200 & 150 & 63 & $10 \times 10$ & graphite & 2 & 280 \\
\hline 24 & $100 \times 100$ & graphite & 2 & 280 & 10 & 200 & 35 & 64 & $100 \times 100$ & copper & 1 & 220 \\
\hline 25 & $100 \times 100$ & graphite & 2 & 160 & 30 & 50 & 150 & 65 & $100 \times 100$ & graphite & 2 & 220 \\
\hline 26 & $100 \times 100$ & copper & 2 & 160 & 30 & 50 & 35 & 66 & $10 \times 10$ & graphite & 1 & 220 \\
\hline 27 & $100 \times 100$ & copper & 2 & 220 & 20 & 125 & 92.5 & 67 & $10 \times 10$ & copper & 2 & 160 \\
\hline 28 & $100 \times 100$ & graphite & 1 & 160 & 10 & 200 & 35 & 68 & $100 \times 100$ & copper & 2 & 280 \\
\hline 29 & $10 \times 10$ & graphite & 1 & 280 & 10 & 200 & 35 & 69 & $10 \times 10$ & graphite & 1 & 160 \\
\hline 30 & $10 \times 10$ & copper & 1 & 160 & 30 & 50 & 35 & 70 & $10 \times 10$ & copper & 1 & 160 \\
\hline 31 & $100 \times 100$ & copper & 1 & 160 & 10 & 200 & 150 & 71 & $100 \times 100$ & copper & 2 & 280 \\
\hline 32 & $10 \times 10$ & copper & 2 & 280 & 10 & 200 & 35 & 72 & $10 \times 10$ & copper & 2 & 220 \\
\hline 33 & $10 \times 10$ & graphite & 2 & 220 & 20 & 125 & 92.5 & 73 & $100 \times 100$ & graphite & 2 & 160 \\
\hline 34 & $10 \times 10$ & graphite & 1 & 160 & 10 & 50 & 35 & 74 & $10 \times 10$ & graphite & 2 & 280 \\
\hline 35 & $100 \times 100$ & copper & 1 & 280 & 30 & 200 & 150 & 75 & $100 \times 100$ & copper & 2 & 160 \\
\hline 36 & $100 \times 100$ & copper & 2 & 280 & 10 & 200 & 150 & 76 & $100 \times 100$ & copper & 1 & 160 \\
\hline 37 & $10 \times 10$ & graphite & 1 & 280 & 30 & 50 & 35 & 77 & $100 \times 100$ & copper & 2 & 160 \\
\hline 38 & $10 \times 10$ & copper & 2 & 280 & 30 & 50 & 35 & 78 & $10 \times 10$ & copper & 2 & 160 \\
\hline 39 & $10 \times 10$ & copper & 2 & 160 & 30 & 200 & 35 & 79 & $10 \times 10$ & graphite & 1 & 160 \\
\hline 40 & $10 \times 10$ & copper & 1 & 280 & 10 & 200 & 150 & 80 & $10 \times 10$ & graphite & 2 & 220 \\
\hline
\end{tabular}




\subsection{Experimental methods}

The samples produced within the project were carefully cleaned of kerosene from the dielectric bath and other impurities generated during erosion. From the samples measuring $100 \times 100 \mathrm{~mm}$, small cubes measuring $5 \times 5 \mathrm{~mm}$ were cut out using a wire electrical discharge machine.Thus, it made it possible to analyse them in the limited spaces of individual devices and subsequently produce metallographic preparations from them. First, the topography of all machined surfaces was analysed using a Dektak XT contact 3D profilometer from Bruker and Vision 64 software. Measurements were performed on 5 samples at 5 random locations, followed by an arithmetic mean. The measurement was performed according to the corresponding standard for profile ISO 4287 [15]. 3D reliefs of surfaces were also obtained on this device, which were further processed in the Gwyddion program. Furthermore, the surfaces of individual samples as well as electrodes were studied by electron microscopy, using an electron microscope (SEM) of the Lyra3 type from the company Tescan. This microscope was further equipped with an energy-dispersive X-ray detector (EDX), which allowed the analysis of the chemical composition. However, the accuracy of this device is $0.5 \mathrm{wt}$ \%, So in order to more accurately study the chemical composition, lamellae for the observation and analysis of the chemical composition were made in a transmission electron microscope (TEM) of the Titan type from ThermoFisher. The individual lamellae were manufactured using SEM of the Helios type from the company ThermoFisher, which was equipped with a focused ion beam (FIB). In order to analyse the condition of the subsurface layer, metallographic preparations were created. These metallographic preparations were prepared by conventional techniques - wet grinding and diamond paste polishing using the automatic preparation system TEGRAMIN 30 from Struers. The final mechanical-chemical finishing was performed using a Struers OPChem suspension. After etching with Nital etchant, the structure of the material was observed and documented by light microscopy on an inverted light microscope Axio Observer Z1m from ZEISS. The subsurface state of the layer was further examined by electron microscopy on Lyra3.

\section{Results And Discussion}

\subsection{Statistical evaluation of eroding rate}

EDM machining is specific according to the erosion rate- the speedof machining - compared to conventional machining methods. The eroding ratecannot be set on the machine within the machining program, but this rateis completely generated by the machine depending on the setting of eroding parameters, such as Open-voltage, Pulse current, Pulse on-time or Pulse off-time. It results in the fact that the electrode can never come into direct contact with the workpiece. During the machining process, the eroding rateis always shown on the machine display, from where it has been rewritten for each sample in the graph shown in Fig. 2. It is clear from the individual erosion ratesthat samples with a shape of $100 \times 100$ m were eroded at the slowest ratesclose to zero. This proves to be normal, since such a large electrode area always allows only very slow material removal. The highest values of the erosion rateof these samples with the size of $100 \times 100 \mathrm{~mm}$ were achieved in Sample 5 (material steel 1.2363 , eroding parameters: $U=280 \mathrm{~V}, l=30 \mathrm{~A}$, Ton=200 $\mu \mathrm{s}$, Toff $=30 \mu \mathrm{s}$ ) and that is $0.00902 \mathrm{~mm} / \mathrm{min}$ using a graphite electrode and using a copper electrode for Sample 76, namely $0.0066 \mathrm{~mm} / \mathrm{min}$. For electrodes measuring $10 x 10 \mathrm{~mm}$, the highest rateof $0.68211 \mathrm{~mm} / \mathrm{min}$ was achieved for Sample 42 (material steel 1.2363, eroding parameters: $U=280 \mathrm{~V}, \mathrm{l}=30 \mathrm{~A}$, Ton=200 $\mu \mathrm{s}$, Toff $=35 \mu \mathrm{s}$ ) using copper electrodes and using a graphite electrode, the highest eroding rate was recorded for Sample 13, namely $0.43901 \mathrm{~mm} / \mathrm{min}$. Unfortunately, similar studies such as Muthuramalingam [20] or Amorim [21] do not report eroding ratesseparately.

Linear regression was used to model the eroding ratev, which assumes homogeneity of residue scatter (deviations from the model) and cannot be achieved due to two-order differences in eroding rate. Therefore, the eroding rateitself was replaced by the order of eroding rate, i.e. the decimal logarithm of the original eroding rate. The influence of categorical input factors on the eroding rate and the order of eroding rate is shown in Fig. 2(b), where the practically zero variability of the eroding rate for $100 \times 100$ samples can be seen.

A regression model of equation (1) was constructed for the order of erosion rate, which describes $97.46 \%$ of the variability of the monitored data. This hierarchical model was created using Stepwise Selection of Terms ( $p$-value $<0.05)$ from a model where all factors and second-order interactions were.

$\operatorname{LogTen}(v)=-2.177-1.0484$ Shape -0.0020 Electrode $+0.02998 I-$

-0.00031 Ton -0.00314 Toff +0.0569 Shape Electrode +0.000013 Ton $\cdot$ Toff ,

where the lower limit for categorical factors is -1 and the upper limit is 1.

The model was adequate, i.e. without the significant influence of factors that were not included in the experiment ( $p$-value $\left.\mathrm{Lack}_{\text {-of-Fit }}=0.059\right)$. Furthermore, the model was without statistically significant quadratic curvature $\left(p-v_{\text {value }}\right.$ Curvature $\left.=0.150\right)$, which could be verified by measurements at central points. The influence of individual factors and interactions on the order of erosion rate, including the p-value test of significance, is shown in Tab. 5 . The effect of these factors and interactions is shown in Fig. 3. The most significant influence is caused by the shape of the electrode and Pulse current, then by the Pulse on-time, Pulse off-time and the electrode material. The last two parameters Material of workpiece and Open voltage are statistically insignificant.

Tab.5 Effect of individual Terms on the order of erosion rate and their significance 


\begin{tabular}{|lll|}
\hline Source & Contribution & P-Value \\
\hline Model & $97.46 \%$ & 0.000 \\
\hline Linear & $97.00 \%$ & 0.000 \\
\hline Shape of electrode & $90.16 \%$ & 0.000 \\
\hline Material of electrode & $0.00 \%$ & 0.922 \\
\hline Pulse current $(\mathrm{A})$ & $6.04 \%$ & 0.000 \\
\hline Pulse on-time $(\mu \mathrm{s})$ & $0.34 \%$ & 0.005 \\
\hline Pulse off-time $(\mu \mathrm{s})$ & $0.46 \%$ & 0.000 \\
\hline 2-Way Interactions & $0.46 \%$ & 0.002 \\
\hline Shape of electrode*Material of electrode & $0.25 \%$ & 0.008 \\
\hline Pulse on-time $(\mu \mathrm{s}) *$ Pulse off-time $(\mu \mathrm{s})$ & $0.21 \%$ & 0.017 \\
\hline Error & $2.54 \%$ & \\
\hline Curvature & $0.07 \%$ & 0.150 \\
\hline Lack-of-Fit & $2.36 \%$ & 0.059 \\
\hline Pure Error & $0.11 \%$ & \\
\hline Total & $100.00 \%$ & \\
\hline
\end{tabular}

\subsection{Surface topography and statistical evaluation}

The topography is qualified by deviations in the direction of the normal vector of the real surface from its perfectly smooth ideal state. It is a topography that represents a key aspect in the behaviour of a real component in interaction with its environment. From the point of view of tribology, smooth surfaces have a lower tendency to wear and lower coefficients of friction than those with higher values of topography parameters. Based on the irregularities of the topography of the surface, it is possible to predict the formation of nucleation sites for cracks or corrosion. The analysis of the surface topography in connection with the setting of the machine parameters is therefore crucial, especially in cases where the part is machined only by EDM without subsequent further finishing technology, usually in the form of grinding. For this reason, 2 profile parameters were evaluated in this experiment, which were the arithmetical mean deviation of the profile ( $\mathrm{Ra}$ ) and the maximum height of the profile ( $\mathrm{Rz})$. The individual values of the topography parameters $R a$ and $R z$ were compiled in a table and shown in Fig. $4(a, b)$. It is obvious that the lowest parameters of the topography were achieved in Sample 3 , with Ra being only $1.75 \mu$ m.This sample had a shape of $100 \times 100 \mathrm{~mm}$, was made of material 1.2363 and machined with a graphite electrode. Thematerial 1.2343ESR was machined with the lowest topographic parameters for Sample 50 and $R a 2 \mu \mathrm{m}$ also using a graphite electrode. The lowest values of the topography parameters for the shape $10 \times 10 \mathrm{~mm}$ were evaluated in Samples 56 from the material 1.2343ESR machined with a graphite electrode and in Sample 34 from the material 1.2363 also machined with a graphite electrode. It is thus clear that by using graphite electrodes it is possible to achieve a higher surface quality and thus lower values of the topography parameters. If we compare these values with the values using an older generator, which were analysed by the Mouralova study [5], we can see an improvement in the reduction of all values of individual parameters. 3D reliefs of the samples with the lowest surface topography values, which were Samples 3 and 50 each of a different material but both machined with a graphite electrode, are shown in Fig. 4 (c,d). From these reliefs, the difference in the size of individual craters is clearly visible, which was caused by different settings of the machine parameters for both samples.It was shown that both topography parameters are dependent ( $p$-value $<0.0005$ ) using Spearman's correlation coefficient, which, unlike Pearson's correlation coefficient, does not assume that the data come from a two-dimensional normal distribution. Hierarchical regression models $(2,3)$ were constructed for both characteristics of the topography Ra and $\mathrm{Rz}$, where, as in the case of the order of erosion rate, the Stepwise Selection of Terms method ( $\mathrm{p}$-value $<0.05)$ was used.

\section{$R a=2.408-0.1685$ Electrodet 0.2088 Vorkpiecet $0.006 \mathrm{I}-0.0008$ on $+0.0007 \mathrm{~T} \cdot$ Ton (2)}

$R z=18.31-2.036$ Shape -1.453 Electrodet $0.166 I-0.002$ Ion $+0.004 I \cdot$ Ton,

where the lower limit for categorical factors is -1 and the upper limit is 1.

Both models are adequate ( $p$-value Lack-of-Fit $>0.05$ ) and without the influence of squares of individual factors ( $p$-value Curvature $>0.05)$. The Ra model describes $77.46 \%$ and the Rz model describes $66.50 \%$ of the variability of the monitored data. The contributions of individual factors to the overall variability of the characteristics Ra and Rz, including their p-value test of significance, are given in Tab. 4. Graphs of the main effects and the only significant interactions are shown in Fig. 5. Fig. 5(a) and Tab. 6show that with respect to both parameters of the topography, the most important factors are Pulse current, Pulse on-time and their mutual interaction. Less significant or insignificant are categorical input variables and numerical factors Open-voltage and Pulse off-time. Fig. 5(b) shows that due to the significant interaction of ${ }^{\star}$ Ton, there is a greater increase in $R a$ and $R z$ with increasing / when Ton is at the upper level.

Tab.6 Increment of individual Terms to Ra and Rz and their significance 


\begin{tabular}{|lllll|}
\hline Source & Contribution Ra & P-Value Ra & Contribution Rz & P-Value Rz \\
\hline Model & $77.46 \%$ & 0.000 & $66.50 \%$ & 0.000 \\
\hline Linear & $67.85 \%$ & 0.000 & $60.22 \%$ & 0.000 \\
\hline Shape of electrode & & & $3.62 \%$ & 0.006 \\
\hline Material of electrode & $1.23 \%$ & 0.049 & $1.85 \%$ & 0.047 \\
\hline Material of workpiece & $1.88 \%$ & 0.015 & & \\
\hline Pulse current (A) & $30.51 \%$ & 0.000 & $30.96 \%$ & 0.000 \\
\hline Pulse on-time $(\mu \mathrm{s})$ & $34.23 \%$ & 0.000 & $23.79 \%$ & 0.000 \\
\hline 2-Way Interactions & $9.62 \%$ & 0.000 & $6.29 \%$ & 0.000 \\
\hline Pulse current $(\mathrm{A}) *$ Pulse on-time $(\mu \mathrm{s})$ & $9.62 \%$ & 0.000 & $6.29 \%$ & 0.000 \\
\hline
\end{tabular}

\subsection{Analysis of surface and subsurface area morphology, including the defects}

The morphology of electrically discharge machined surfaces forms a so-called random topographic profile. Thus, there are no periodically recurring elements of the topography, such as during turning, when there is a constantly recurring groove on the surface from the blade of the turning knife.Large craters are formed on EDM surfaces after individual electric discharges.Also here the eroded material adheres in the form of small spheres, which has not been washed away by the dielectric liquid stream. Due to the effects of short-term electric discharges (in the order of microseconds), not only the individual particles of material are eroded but also the evaporation of thematerial due to very high temperatures of $10000-20000^{\circ} \mathrm{C}$ [16]. Another undesirable effect of the process is the relatively frequent occurrence of defects in the form of cracks, which can only lead within the recast layer (completely melted and re-cooled layer) or can interfere with the base material. The occurrence of such cracks can significantly reduce the service life or proper functionality of machined parts, so it is essential that their occurrence on machined surfaces is as small or preferably none. During the whole analysis on an electron microscope, a backscattered electron detector (BSE) was used, always first with a magnification of 150x and then with 500x.

Fig. 6 shows the morphologies of different samples, which differ significantly from each other. Sample 50 made of $1.2343 E S R$ steel machined with a $100 x 100$ $\mathrm{mm}$ graphite electrode with the second lowest surface topography parameters was chosen as the first representative (see Fig. 6 (a)). Although its surface did not have the lowest Ra and Rz values, it was not covered by any cracks. In contrast, Sample 3 made of 1.2363 steel machined with a graphite electrode with a shape of $100 \times 100 \mathrm{~mm}$ with the lowest topography parameters, which is shown in Fig. 6(c), was completely covered with a network of cracks. These cracks were further analysed in a cross section to assess whether they were only within the recast layer or interfering with the base material. The cracks on EDM machined surfaces are a common phenomenon, which was presented in, for example, the study by Rajendran [7], Guu [28], Tai [22] or Mandal [23]. Further for the comparison, Fig. 6(b) shows the morphology of Sample 42 made of 1.2363 steel machined with a $10 \times 10$ mm copper electrode, which had the lowest topography parameters. A large amount of recast layer is visible on its surface, as well as numerous burnt places, which are mainly made up of carbon. This is a surface condition that is unsuitable for the components, and this setting of the machine parameters can also be assessed in this way. From the chemical composition analysis shown in Fig. 6(b), it is apparent that there was no diffusion of electrode material into the workpiece. For samples that have been machined with a graphite electrode, this cannot be assessed because the material being machined contains carbon and carbon also forms a common contamination of surfaces. Diffusion processes from the tool electrode to the base material were not monitored in the case of using a copper electrode in Mouralová study [5], but when machining the $\mathrm{TiB}_{2}$ material in the Torres study [24] they were already studied.

Due to a detailed study of the condition of the subsurface layer, metallographic cross-sectional preparations of all samples were made. The analysis was performed using electron microscopy, using a BSE detector, always with a magnification of $1000 x$ and then $2500 x$ and $4000 x$. The condition of the subsurface layer (see Fig. 7) is crucial, especially in terms of proper functionality and predicted service life of manufactured components. It makes it necessary to carefully analyse it. For this purpose, the condition of each sample was examined, while the presence of defects in the form of cracks was recorded on individual samples and is compiled in Tab. 7. Overall, cracks were detected in 25 samples out of a total of 80 . This is a significantresult since in comparison with the use of the old type of generator in Mouralová study [5] in the same design of experiment, 41 samples with cracks from a total of 80 samples were detected. More prone surfaces for the formation of cracks are those that were machined with a graphite electrode in a total of 15 cases out of 25 and in the same number of cases the cracks have samples made with the shape of the electrode $100 \times 100$ mm. However, the cracks, as can be seen in Fig. 7 (c-h) have changed their character and extend across the entire recast layer to the base material or even originated in the base material. Cracks extending through the recast layer to the base material were also studied in the Lee study [25] during D2 steel machining, and cracks arising in the base material also appeared during the Hastelloy X machining in the Kang study [26]. These cracks are very dangerous because they can prematurely end the service life of the part produced. Cracks also occurred during machining of titanium alloy Ti-6Al-4V in study by Das [27] or Phan [28], or also while machining Zirconia-Toughened Alumina Ceramic in the study by Bilal [29].

Tab. 7 Analysis of the occurrence of defects on the surface of individual samples. 


\begin{tabular}{|llllllllll|}
\hline Sample no. & defects & Sample no. & defects & Sample no. & defects & Sample no. & defects & Sample no. & defects \\
\hline $\mathbf{1}$ & No & $\mathbf{1 7}$ & No & $\mathbf{3 3}$ & No & $\mathbf{4 9}$ & Yes & $\mathbf{6 5}$ & No \\
\hline $\mathbf{3}$ & No & $\mathbf{1 8}$ & No & $\mathbf{3 4}$ & No & $\mathbf{5 0}$ & No & $\mathbf{6 6}$ & No \\
\hline $\mathbf{4}$ & Yes & $\mathbf{1 9}$ & No & $\mathbf{3 5}$ & Yes & $\mathbf{5 1}$ & Yes & $\mathbf{6 7}$ & No \\
\hline $\mathbf{5}$ & No & $\mathbf{2 0}$ & No & $\mathbf{3 6}$ & No & $\mathbf{5 2}$ & No & $\mathbf{6 8}$ & No \\
\hline $\mathbf{6}$ & Yes & $\mathbf{2 1}$ & Yes & $\mathbf{3 7}$ & No & $\mathbf{5 3}$ & No & $\mathbf{6 9}$ & No \\
\hline $\mathbf{7}$ & No & $\mathbf{2 2}$ & Yes & $\mathbf{3 8}$ & No & $\mathbf{5 4}$ & Yes & $\mathbf{7 0}$ & No \\
\hline $\mathbf{8}$ & No & $\mathbf{2 3}$ & No & $\mathbf{3 9}$ & No & $\mathbf{5 5}$ & Yes & $\mathbf{7 1}$ & No \\
\hline $\mathbf{9}$ & Yes & $\mathbf{2 4}$ & Yes & $\mathbf{4 0}$ & Yes & $\mathbf{5 6}$ & No & $\mathbf{7 2}$ & No \\
\hline 10 & Yes & $\mathbf{2 5}$ & No & 41 & No & $\mathbf{5 7}$ & Yes & $\mathbf{7 3}$ & Yes \\
\hline 11 & No & $\mathbf{2 6}$ & No & $\mathbf{4 2}$ & No & $\mathbf{5 8}$ & No & $\mathbf{7 4}$ & Yes \\
\hline 12 & No & $\mathbf{2 7}$ & No & $\mathbf{4 3}$ & Yes & $\mathbf{5 9}$ & Yes & $\mathbf{7 5}$ & No \\
\hline 13 & No & $\mathbf{2 8}$ & Yes & $\mathbf{4 4}$ & No & $\mathbf{6 0}$ & No & $\mathbf{7 6}$ & Yes \\
\hline 14 & No & $\mathbf{2 9}$ & Yes & $\mathbf{4 5}$ & No & $\mathbf{6 1}$ & No & $\mathbf{7 7}$ & No \\
\hline 15 & Yes & $\mathbf{3 0}$ & No & $\mathbf{4 6}$ & No & $\mathbf{6 2}$ & Yes & $\mathbf{7 8}$ & No \\
\hline 16 & No & $\mathbf{3 1}$ & Yes & $\mathbf{4 7}$ & No & $\mathbf{6 3}$ & No & $\mathbf{7 9}$ & No \\
\hline
\end{tabular}

Binary logistic regression was used to analyse the occurrence of defects, where insignificant members were removed from the model containing all factors and all second-order interactions using the Stepwise Selection method ( $p$-value $=0.05$ ). Only the factors Pulse current, Pulse on-time and Material of workpiece proved to be statistically significant, their effect on the probability of occurrence of the defect is shown in Fig. 8 (a).It can be seen that the number of defects decreases with increasing Pulse current and the number of defects increases with increasing Pulse on-time.Workpiece material 2 (steel 1.2343ESR) is of a significantly higher quality than 1 (steel 1.2363) due to the number of defects. Of all the second-order interactions, only the Pulse current *Material of workpiece interaction was significant, the effect of which on the probability of occurrence of the defect is shown in Fig. 1. 8 (b). The regression equation itself for the probability of occurrence of defects for individual materials is given by relations $(4,5)$ and shown in Fig. $8(\mathrm{c})$, where it can be seen that Material 2 is significantly better with respect to the number of surface defects.

Regression Equation for Material of Workpiece 1:

$P($ defects $)=\exp (-1.223-0.192 I+0.0363$ Ton $) /(1+\exp (-1.223-0.192 I+0.0363$ Ton $))$

Regression Equation for Material of Workpiece 2:

$P($ defects $)=\exp (-4.593-0.143+0.0363$ on $) /(1+\exp (-4.593-0.143+0.0363$ on $))$

\subsection{Analysis of the surface morphology of worn electrodes}

Due to the very high temperatures arising during eroding, not only the workpiece but also the tool used, which in this case is the electrode, is exposed to its consequences. These electrodes are not only worn in terms of the removal of the material itself, which was presented, for example, in the Jameson study [17], but another type of their wear is diffusion. The diffusion processes are very pronounced, as can be seen in Fig. 9 on both copper and graphite electrodes. On the other hand, it should be mentioned that the machined surfaces of the individual samples were not contaminated with elements from the tool electrodes.Thus, it can be said that the diffusion took place only from the workpiece to the electrode. The same process of one-sided diffusion was recorded when machining AA6061/10\% SiC composite in the Singh study [18]. In contrast, the diffusion of electrode elements, specifically copper, into the machined surface occurred during machining of tungsten carbide in the Lee study [19].

\subsection{TEM lamella analysis}

The lamella made of a sample of 1.2363 steel machined with a copper electrode was studied using a transmission electron microscope in terms of changes in the distribution of individual elements due to machining. The chemical distribution was analysed from EDX spectra taken on a Titan G2 microscope at an accelerating voltage of $300 \mathrm{kV}$. During the measurement itself, the microscope was set to scan mode with a beam current of $0.8 \mathrm{nA}$, which was sufficient to generate the X-rays needed for the EDX analysis. The average time of one measurement did not exceed 10 min. Due to the type of material, the protective carbon layer was damaged in some places during the production of the lamella, which is evident from the picture of the manufactured lamella shown in Fig. 10. During EDX measurements, attention was paid to 2 places. The first (EDX 1) covered the entire lamella part and the second (EDX 2) focused in more detail on the detected particles in the upper half of the scan. From the measured spectra of the individual elements in Fig. 10, damage to the carbon cover layer is clearly visible. In addition, particles consisting of chromium, manganese, molybdenum, vanadium and carbon in the iron matrix were observed. Furthermore, individual vanadium particles were present and a homogeneous distribution of copper and silicon was also observed. The uniform distribution of 
copper probably results from the secondary redeposition during the thinning of the lamella on the copper holder. In the upper primarily affected EDM layer of 2 $\mu \mathrm{m}$, the individual elements were distributed evenly up to an increased concentration of manganese, silicon and vanadium in the area close to the protective carbon layer. Furthermore, there was an increased concentration of copper, which in this case probably comes from a copper EDM electrode. A closer examination of the particle in Fig. 10 showed that the individual rays are formed by an increased concentration of chromium, while the presence of individual particles formed by vanadium was also confirmed. The exact chemical composition for both EDX 1 and EDX 2 scans is given in Tab. 8. Comparing the chemical composition of the measured areas, it was found that in the case of a more detailed examination of the lamella on EDX 2.There was an increase in carbon, silicon and iron concentrations compared to EDX 1. Elements such as vanadium, chromium, manganese, copper and molybdenum decreased.

Table 8 Analysis of the chemical composition in individual places according to Fig. 10.

\begin{tabular}{|lllll|}
\hline Element & EDX 1 & \multicolumn{3}{c|}{ EDX 2 } \\
\cline { 2 - 5 } & Atomic Fraction (\%) & Atomic Error (\%) & Atomic Fraction (\%) & Atomic Error (\%) \\
\hline C & 1.41 & 0.29 & 2.98 & 0.61 \\
\hline Si & 0.37 & 0.10 & 0.39 & 0.11 \\
\hline V & 0.17 & 0.04 & 0.15 & 0.04 \\
\hline Cr & 5.39 & 1.31 & 4.17 & 1.02 \\
\hline Mn & 0.79 & 0.19 & 0.76 & 0.19 \\
\hline Fe & 87.22 & 21.14 & 87.27 & 21.28 \\
\hline Cu & 4.14 & 1.00 & 3.92 & 0.96 \\
\hline Mo & 0.50 & 0.12 & 0.37 & 0.09 \\
\hline
\end{tabular}

The prepared lamella from a sample of 1.2343ESR steel machined with a carbon electrode was also analysed in TEM, the accelerating voltage, current and setting of the whole device being the same as in the case of the first lamella. A total of 2 chemical composition analyses were performed, with the first (EDX 1 ) examining the entire lamella and the second (EDX 2) examining its detail. The lamella itself and EDX 1 are shown in Fig. 11, it being clear that in the area of the upper part of the lamella ( $2 \mu \mathrm{m}$ from the surface) all elements were evenly distributed up to the surface area in which the concentration of manganese, vanadium and silicon increased. In the remaining part of the lamellae, as in the case of the first lamellae, they consisted of vanadium, chromium, manganese and molybdenum. In addition, individual vanadium particles were detected. EDX 2 led to the same conclusion as in the case of the first lamella, that the core of the particles is formed by a network of chromium veins. The chemical composition from the EDX 1 and EDX 2 sites was summarized in Tab. 9 . A comparison of individual areas of EDX measurements with respect to the total concentration of individual elements shows an increase in carbon, vanadium and manganese in the case of EDX 2 measurements. The only element in which there was no change in concentration was silicon. The lamella formed from the EDM workpiece was also investigated in Mouralova's study [5], where the same materials were machined only using the old version of the generator. It was found that essentially no changes were achieved here. The TEM lamella made of EDM machined material was also created and analysed in the Murray study [30] when machining austenitic steel or also when machining single-crystal silicon in the Murray study [31].

Tab.9 Analysis of the chemical composition in individual places according to Fig. 11.

\begin{tabular}{|lllll|}
\hline \multirow{2}{*}{ Element } & EDX 1 & \multicolumn{3}{c|}{ EDX 2 } \\
\cline { 2 - 5 } & Atomic Fraction (\%) & Atomic Error (\%) & Atomic Fraction (\%) & Atomic Error (\%) \\
\hline $\mathrm{C}$ & 1.20 & 0.26 & 1.41 & 0.30 \\
$\mathrm{Si}$ & 0.30 & 0.09 & 0.30 & 0.09 \\
\hline $\mathrm{V}$ & 0.18 & 0.04 & 0.21 & 0.05 \\
\hline $\mathrm{Cr}$ & 5.27 & 1.33 & 5.12 & 1.29 \\
$\mathrm{Mn}$ & 0.80 & 0.20 & 0.82 & 0.21 \\
\hline $\mathrm{Fe}$ & 91.84 & 23.11 & 91.77 & 23.10 \\
\hline $\mathrm{Mo}$ & 0.40 & 0.10 & 0.38 & 0.09 \\
\hline
\end{tabular}

\section{Conclusions}

As part of the testing of a completely new energy-saving and powerful EDM generator, samples of 1.2363 and 1.2343 ESR steels were produced according to an extensive design of experiment of 80 rounds, which were subsequently subjected to many analyses and statistical evaluations, which brought the following conclusions:

- at the slowest rates close to zero, samples with the shape of $100 \times 100$ m were eroded, the highest values of the erosion rate of these samples with the size of $100 \times 100 \mathrm{~mm}$ were achieved for Sample 5 (material steel 1.2363 , erosion parameters: $U=280 \mathrm{~V}, l=30 \mathrm{~A}$, Ton=200 $\mu \mathrm{s}$, Toff $=30 \mu \mathrm{s}$ ), namely 0.00902

Page $10 / 23$ 
$\mathrm{mm} / \mathrm{min}$ using a graphite electrode. For electrodes with a size of $10 \times 10 \mathrm{~mm}$ the highest rate of $0.68211 \mathrm{~mm} / \mathrm{min}$ was achieved for Sample 42 (material steel 1.2363, erosion parameters: $U=280 \mathrm{~V}, l=30 \mathrm{~A}$, Ton $=200 \mu \mathrm{s}$, Toff $=35 \mu \mathrm{s})$ using a copper electrode,

- the shape of the electrode and Pulse current have the most significant influence on the erosion rate, Pulse on-time, Pulse off-time and electrode material are also significant,

- the lowest topography parameters were achieved in Sample 3 (material steel 1.2363 , shape $100 \times 100 \mathrm{~mm}$, graphite electrode, erosion parameters: $U=280$ $\mathrm{V}, \mathrm{l}=10 \mathrm{~A}, \mathrm{Ton}=50 \mu \mathrm{s}, \mathrm{Toff}=35 \mu \mathrm{s}$ ) and Ra only $1.75 \mu \mathrm{m}$, while it was found that by using graphite electrodes it is possible to achieve lower values of topography parameters,

- the most important factors influencing the surface topography were Pulse current, Pulse on-time and their mutual interaction, with this significant interaction leading to a greater increase in the topography parameters $R a$ and $R z$ with increasing Pulse current when Pulse on- is at the upper level,

- from the surface and subsurface analysis it is clear that cracks (extending over the entire recast layer to the base material or even formed in the base material) were detected in 25 samples out of a total of 80 , with more prone cracking surfaces being those machined with graphite electrode in a total of 15 cases out of 25 and in the same number of cases cracks have samples made with the shape of the electrode $100 \times 100 \mathrm{~mm}$,

- statistically significant factors influencing the occurrence of defects turned out to be Pulse current, Pulse on-time and Material of workpiece where it can be seen that material 2 (steel 1.2343ESR) is significantly less prone to the formation of surface defects,

- the diffusion processes were very significant on the electrodes used, but the machined surfaces of the individual samples were not contaminated with elements from the tool electrodes. Thus, it can be said that the diffusion took place only from the workpiece to the electrode,

- TEM analysis of lamellae showed the presence of particles consisting of chromium, manganese, molybdenum, vanadium and carbon in the iron matrix.

Based on the above conclusions, it can be stated that the new energy-saving and powerful generator of EDM, clearly contributed to increasing the competitiveness of this production technology and allows efficient machining of parts with excellent surface quality.

\section{Declarations}

Funding:

This work was supported by the Technology Agency of the Czech Republic, project no. TJ02000311.

CzechNanoLab project LM2018110 funded by MEYS CR is gratefully acknowledged for the financial support of the measurements/sample fabrication at CEITEC Nano Research Infrastructure.

This publication is a result of the project CACTU, Reg. No. CZ.02.1.01/0.0/0.0/17_049/0008397, which has been co-financed by European Union from the European Regional Development Fund through the Operational Programme Research, Development and Education. This project has also been financially supported by the Ministry of Industry and Trade of the Czech Republic which has been providing institutional support for long-term conceptual development of research organisation. The project CACTU has been integrated into the National Sustainability Programme I of the Ministry of Education, Youth and Sports of the Czech Republic (MEYS) through the project Development of the UniCRE Centre (L01606).

This work was supported by the Brno University of Technology Specific Research Program, project no. FSI-S-20-6187.

Conflict of Interest:

Authors K. Mouralova, J. Bednar, L. Benes, A. Polzer,R. Zahradnicek, J. Fries, T. Prokes, declares that they have no conflict of interest.

Author Contributions Statement:

Katerina Mouralova: Conceptualization, Methodology, Data curation, Writing- Original draft preparation, Writing- Reviewing and Editing, Supervision. Josef Bednar: Validation, Visualization, Funding acquisition, Formal analysis. Libor Benes: Methodology, Data curation, Funding acquisition. Ales Polzer: Methodology, Funding acquisition. Radim Zahradnicek: Data curation, Methodology. Jiri Fries: Data curation, Funding acquisition. Tomas Prokes: Methodology, Data curation.

\section{References}

[1] K. H. Ho, S. T. Newman, State of the art electrical discharge machining (EDM), International Journal of Machine Tools and Manufacture 43 (13) (2003) 1287-1300.

[2]N. M. Abbas, D. G. Solomon,M. F. Bahari, A review on current research trends in electrical discharge machining (EDM). International Journal of machine tools and Manufacture, 47(7-8)(2007) 1214-1228.

[3]S. Kumar, R. Singh, T. P. Singh,B. L. Sethi, Surface modification by electrical discharge machining: A review. Journal of Materials Processing Technology, 209(8) (2009) 3675-3687.

[4]R. Świercz, D. Oniszczuk-Świercz,T. Chmielewski, Multi-response optimization of electrical discharge machining using the desirability function. Micromachines, 10(1)(2019) 72. 
[5]K. Mouralova, L. Benes, J. Bednar, R. Zahradnicek, T. Prokes, J. Fries, Analysis of Machinability and Crack Occurrence of Steels 1.2363 and 1.2343 ESR Machined by Die-Sinking EDM. Coatings, 10(4) (2020) 406.

[6]D. H. Lee, N. Malhotra,D. W. Jung, Multi characteristic optimization in die sinking EDM of En31 tool steel using utility concept. In 2017 8th International Conference on Mechanical and Aerospace Engineering,(2017) 166-170.

[7]L'. Straka,S. Hašová, Optimization of material removal rate and tool wear rate of Cu electrode in die-sinking EDM of tool steel. The International Journal of Advanced Manufacturing Technology, 97(5-8)(2018) 2647-2654.

[8]R. Purohit, R. S. Rana, R. K. Dwivedi, D. Banoriya, S. K. Singh, Optimization of electric discharge machining of M2 tool steel using grey relational analysis. Materials Today: Proceedings, 2(4-5)(2015) 3378-3387.

[9]A. Molinetti, F. L. Amorim, P. C. Soares, T. Czelusniak, Surface modification of AISI H13 tool steel with silicon or manganese powders mixed to the dielectric in electrical discharge machining process. The International Journal of Advanced Manufacturing Technology, 83(5-8)(2016) 1057-1068.

[10]L. Prasad, A. Gupta, An experimental investigation of machining parameters for EDM using copper electrode of Aisi P20 tool steel. Asian J SciTechnol, 8(01)(2017) 4106-4111.

[11]P. Laxminarayana,N. Aravindan, Study of surface morphology on micro machined surfaces of AISI 316 by Die Sinker EDM. Materials Today: Proceedings, $4(2)(2017)$ 1285-1292.

[12]R. Świercz, D. Oniszczuk-Świercz, Experimental investigation of surface layer properties of high thermal conductivity tool steel after electrical discharge machining. Metals, 7(12)(2017) 550.

[13]A. Al-Khazraji, S. A. Amin,S. M. Ali, The effect of SiC powder mixing electrical discharge machining on white layer thickness, heat flux and fatigue life of AISI D2 die steel. Engineering science and technology, an international journal, 19(3)(2016) 1400-1415.

[14]N. K. Singh, Y. Singh, S. Kumar,A. Sharma, Comparative study of statistical and soft computing-based predictive models for material removal rate and surface roughness during helium-assisted EDM of D3 die steel. SN Applied Sciences, 1(6)(2019) 529.

[15]Geometrical Product Specifications (GPS) -Surface texture: Profile method -Terms, definitions and surface texture parameters. ISO 4287 (1997). Geneva: International Organization for Standardization.

[16] J. A. McGeough, Advanced methods of machining. Springer Science \& Business Media (1988).

[17] E. C. Jameson, Electrical discharge machining (2001) ISBN 08-726-3521-X.

[18]B. Singh, J. Kumar,S. Kumar, Influences of process parameters on MRR improvement in simple and powder-mixed EDM of AA6061/10\% SiC composite. Materials and Manufacturing Processes, 30(3)(2015) 303-312.

[19]S. H. Lee, X. Li, Study of the surface integrity of the machined workpiece in the EDM of tungsten carbide. Journal of materials processing technology, $139(1-3)(2003) 315-321$.

[20]T. Muthuramalingam,B. Mohan, Performance analysis of iso current pulse generator on machining characteristics in EDM process. Archives of Civil and Mechanical engineering, 14(2014) 383-390.

[21]F. L. Amorim,W. L. Weingaertner, The influence of generator actuation mode and process parameters on the performance of finish EDM of a tool steel. Journal of Materials Processing Technology, 166(3) (2005) 411-416.

[22]T. Y. Tai, S. J. Lu, Y. H. Chen, Surface crack susceptibility of electrodischarge-machined steel surfaces. The International Journal of Advanced Manufacturing Technology, 57(9-12) (2011) 983.

[23] P. Mandal, S. C. Mondal, Surface characteristics of mild steel using EDM with Cu-MWCNT composite electrode. Materials and Manufacturing Processes, 34(12) (2019) 1326-1332.

[24] A. Torres, C. J. Luis, I. Puertas, EDM machinability and surface roughness analysis of TiB2 using copper electrodes. Journal of Alloys and Compounds, 690 (2017) 337-347.

[25]H. T. Lee,T. Y. Tai, Relationship between EDM parameters and surface crack formation. Journal of Materials Processing Technology, 142(3)(2003) 676-683.

[26] S. H. Kang, D. E. Kim, Effect of electrical discharge machining process on crack susceptibility of nickel based heat resistant alloy. Materials Science and Technology, 21(7) (2005) 817-823.

[27] S. Das, S. Paul,B. Doloi, A gap-activeelectrical discharge machining (GA-EDM) to rectifythetexturaldefectsoftheprocessedsurface.

JournalofManufacturingProcesses, 64, (2021) 594-605.

[28] N. H. Phan, P. Van Dong, H. T. Dung, N. Van Thien, T. Muthuramalingam, S. Shirguppikar,... \&N. T. Ly, Multi-objectoptimizationof EDM by Taguchi-DEAR methodusingAICrNicoatedelectrode. The International JournalofAdvancedManufacturing Technology, (2021) 1-7.

Page $12 / 23$ 
[29]A. Bilal, A. Perveen, D. Talamona,M. P. Jahan, UnderstandingMaterialRemovalMechanism and EffectsofMachiningParametersduring EDM ofZirconiaToughenedAluminaCeramic. Micromachines, 12(1) (2021) 67.

[30]J. W. Murray, J. C. Walker, A. T. Clare, Nanostructures in austeniticsteelafter EDM and pulsedelectronbeamirradiation. Surface and Coatings Technology, 259 (2014) 465-472.

[31]J. W. Murray, M. W. Fay, M. Kunieda, A. T. Clare, TEM study on theelectricaldischargemachinedsurfaceof single-crystalsilicon. JournalofMaterialsProcessing Technology, 213(5) (2013) 801-809.

\section{Figures}
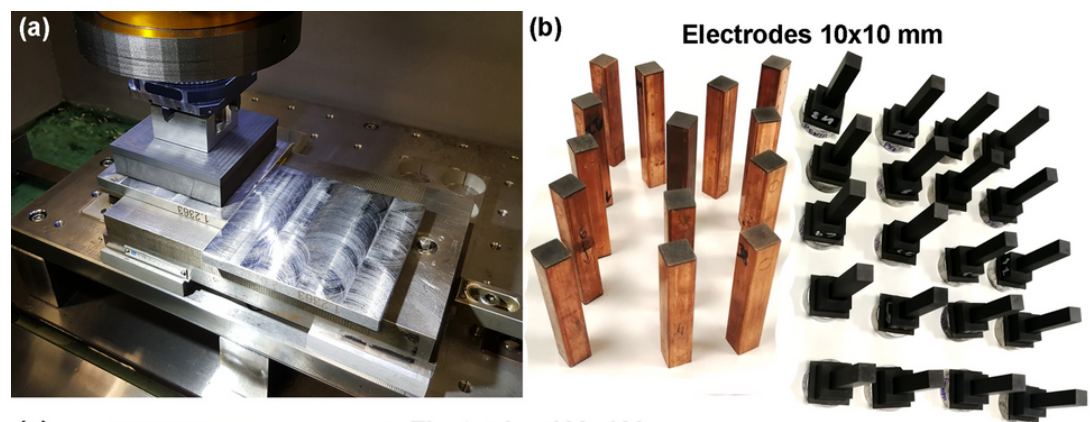

(c) Electrodes $100 \times 100 \mathrm{~mm}$
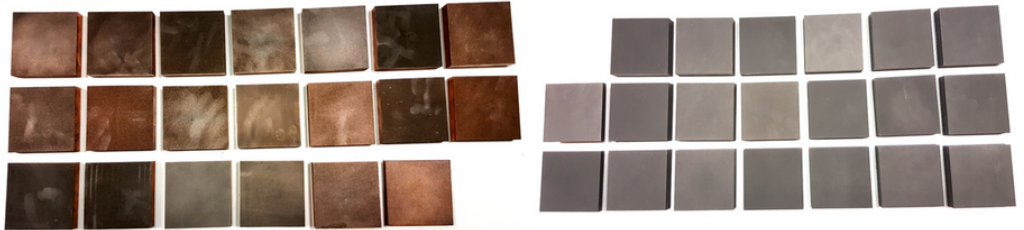

(d)
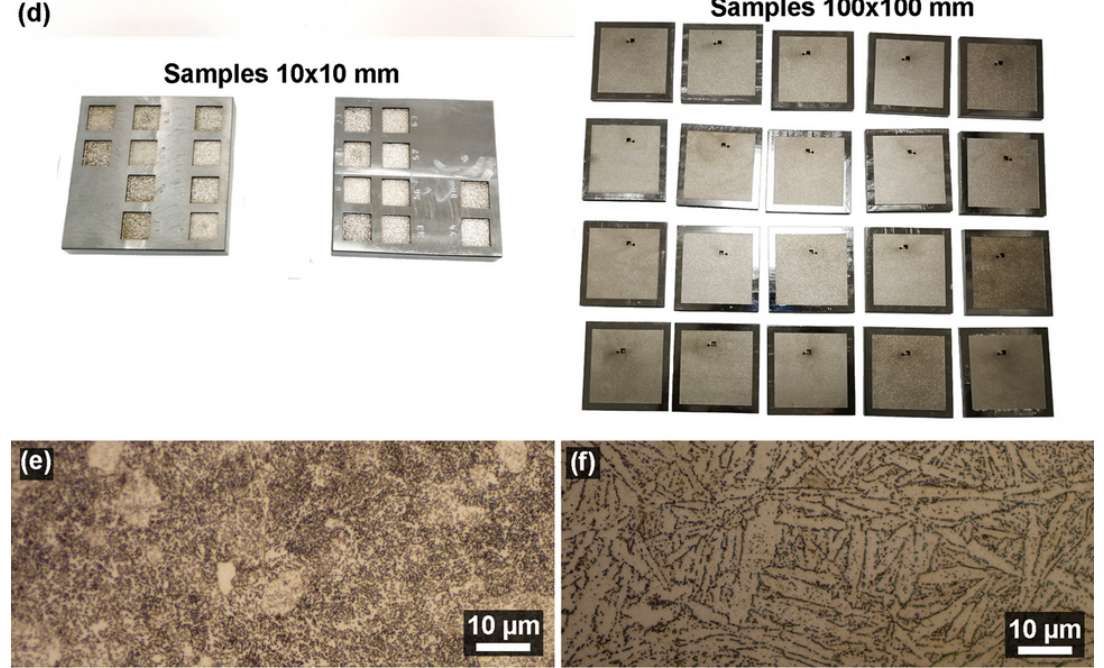

Figure 1

(a) eroding process, (b) graphite and copper electrodes 10x10 mm, (c) graphite and copper electrodes 100x100 mm, (d) double-sided samples 10x10 mm $100 \times 100 \mathrm{~mm},(\mathrm{e})$ the representation of the microstructure (LM) of 1.2363 steel, $(\mathrm{f})$ the representation of the microstructure (LM) of steel $1.2343 \mathrm{ESR}$. 


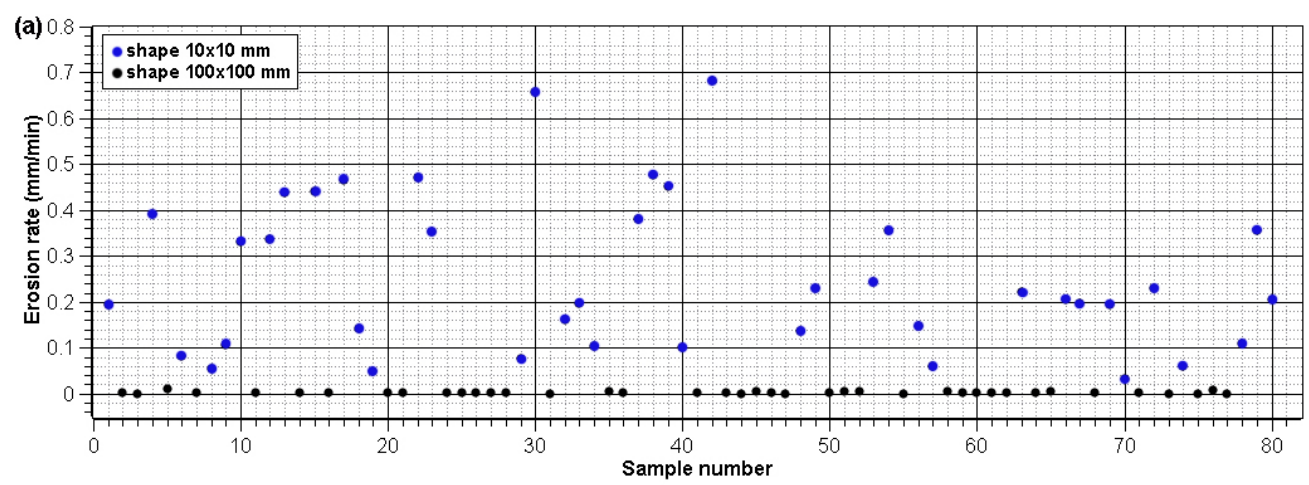

(b) Multi-Vari Chart for Erosion rate ( $\mathrm{mm} / \mathrm{min})$

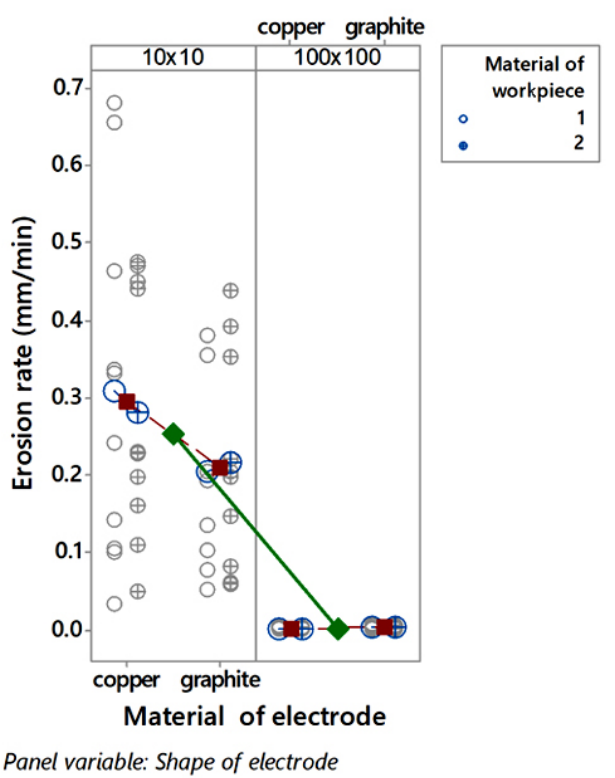

Multi-Vari Chart for LogTen(v)

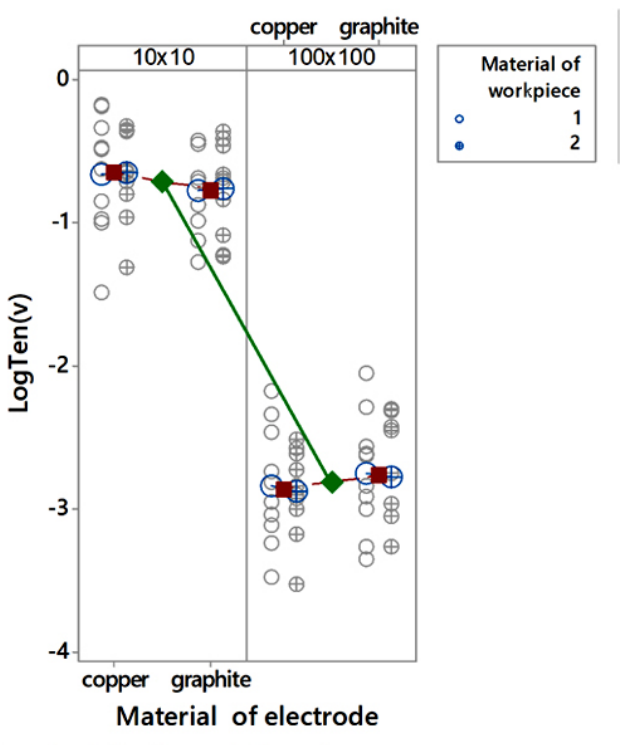

Panel variable: Shape of electrode

\section{Figure 2}

(a) erosion rates of individual samples, (b) Multi-vari chart for the eroding rate and order erosion rate. 

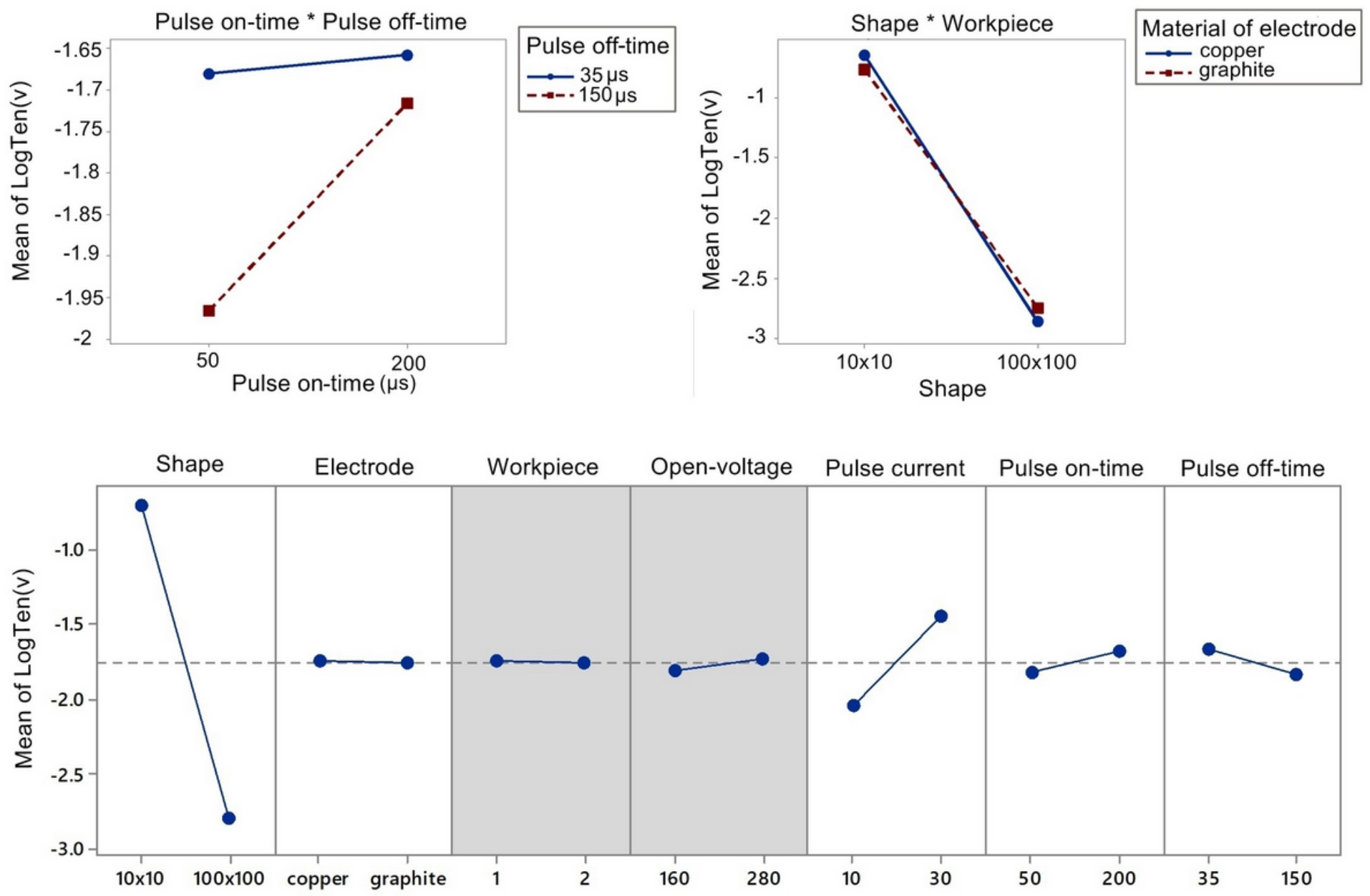

A gray background represents a term not in the model.

Figure 3

Main effects and interactions for LogTen(v). 

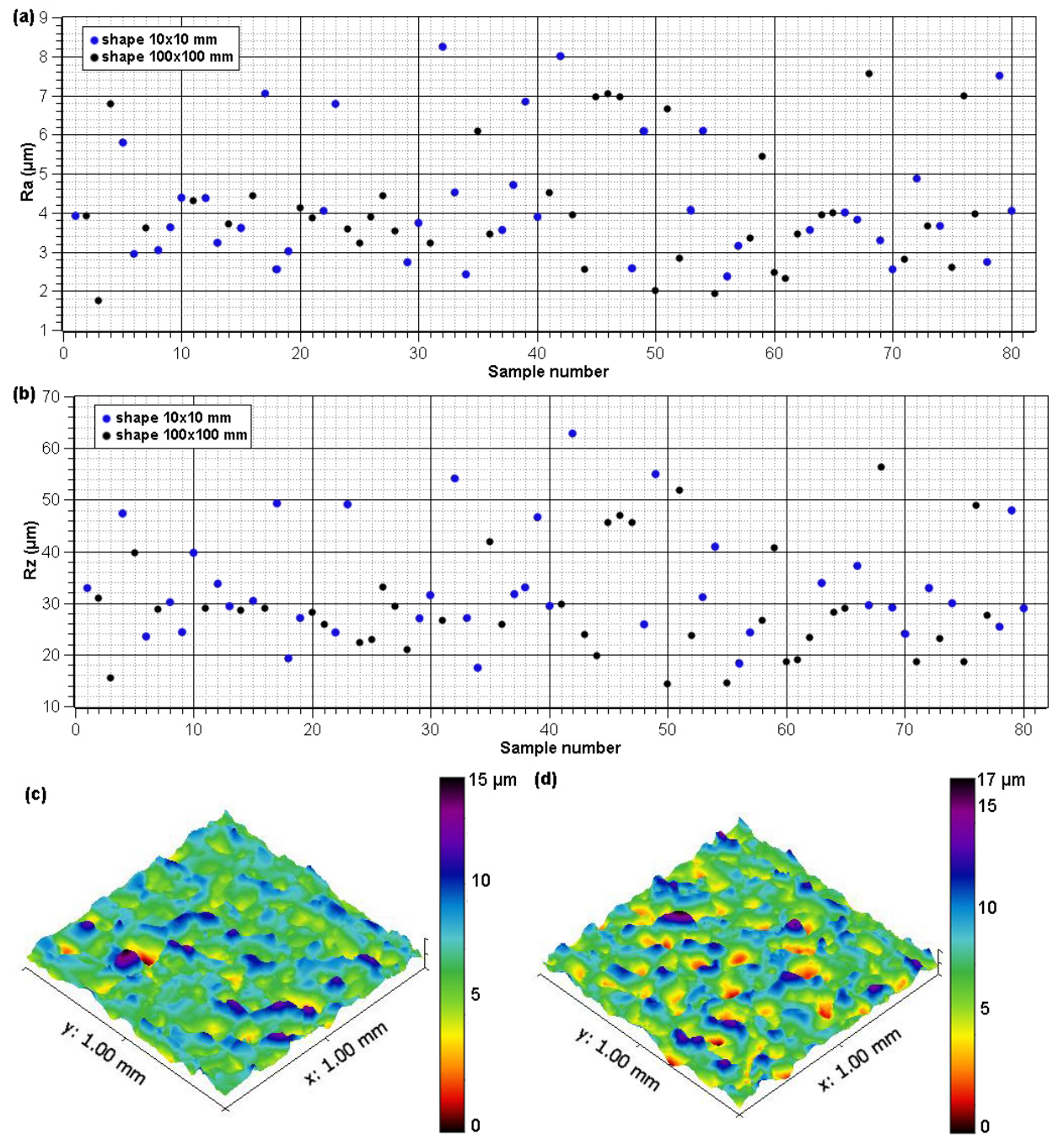

\section{Figure 4}

(a) evaluated parameters $\mathrm{Ra}$, (b) evaluated parameters Rz, (c) 3D relief of Sample 3 made of steel 1.2363 machined with graphite electrode, (d) 3D relief of Sample 50 made of steel 1.2343 ESR machined with graphite electrode. 

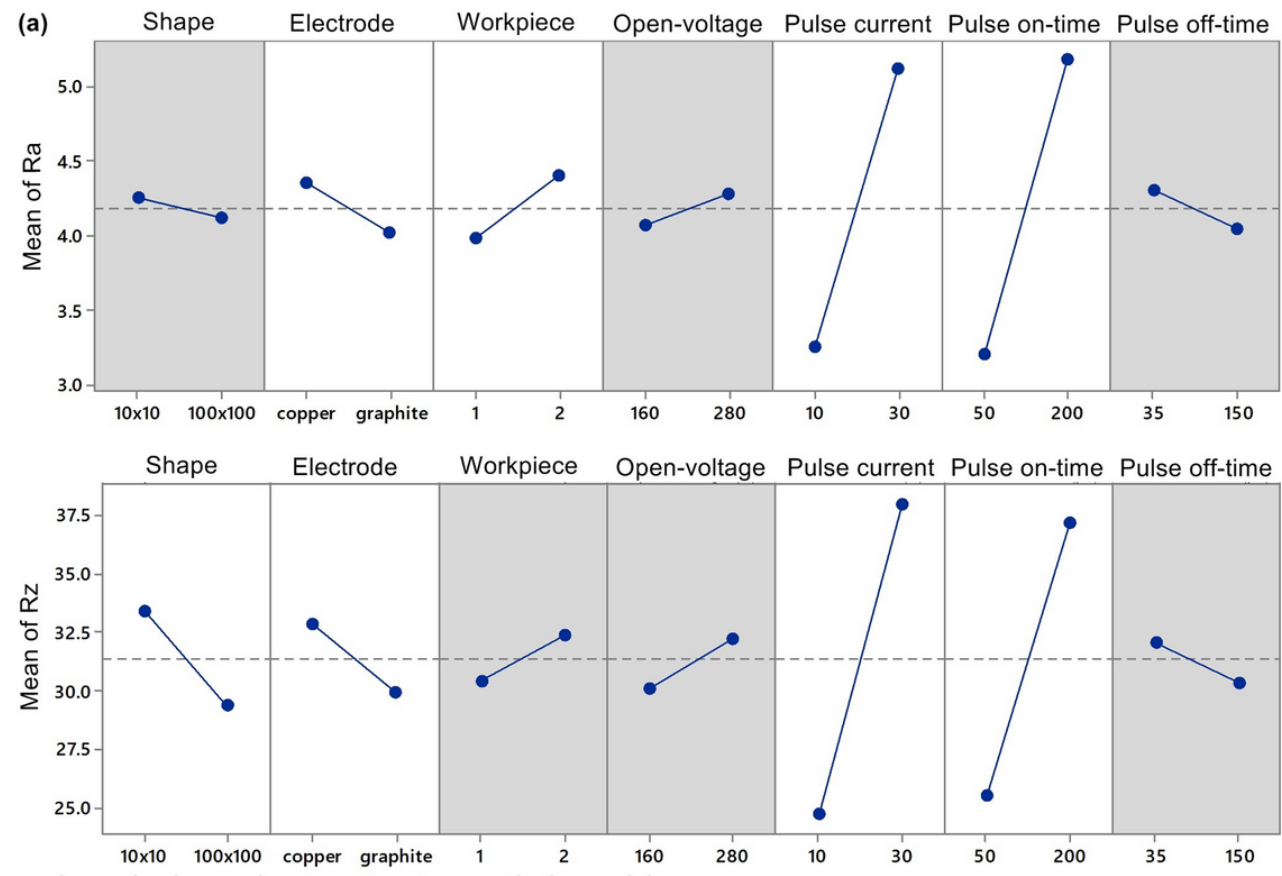

A gray background represents a term not in the model

(b)
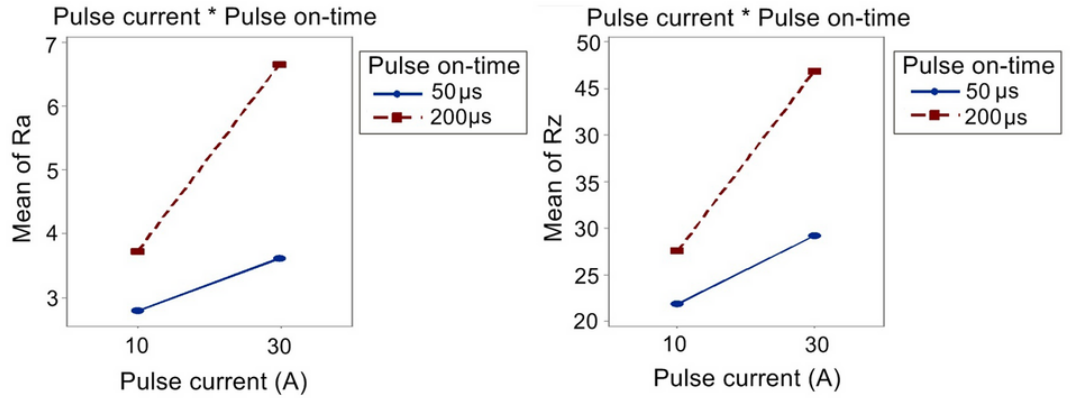

Figure 5

(a) Main effect plot for Ra and Rz , (b) Interaction plot for Ra and Rz. 

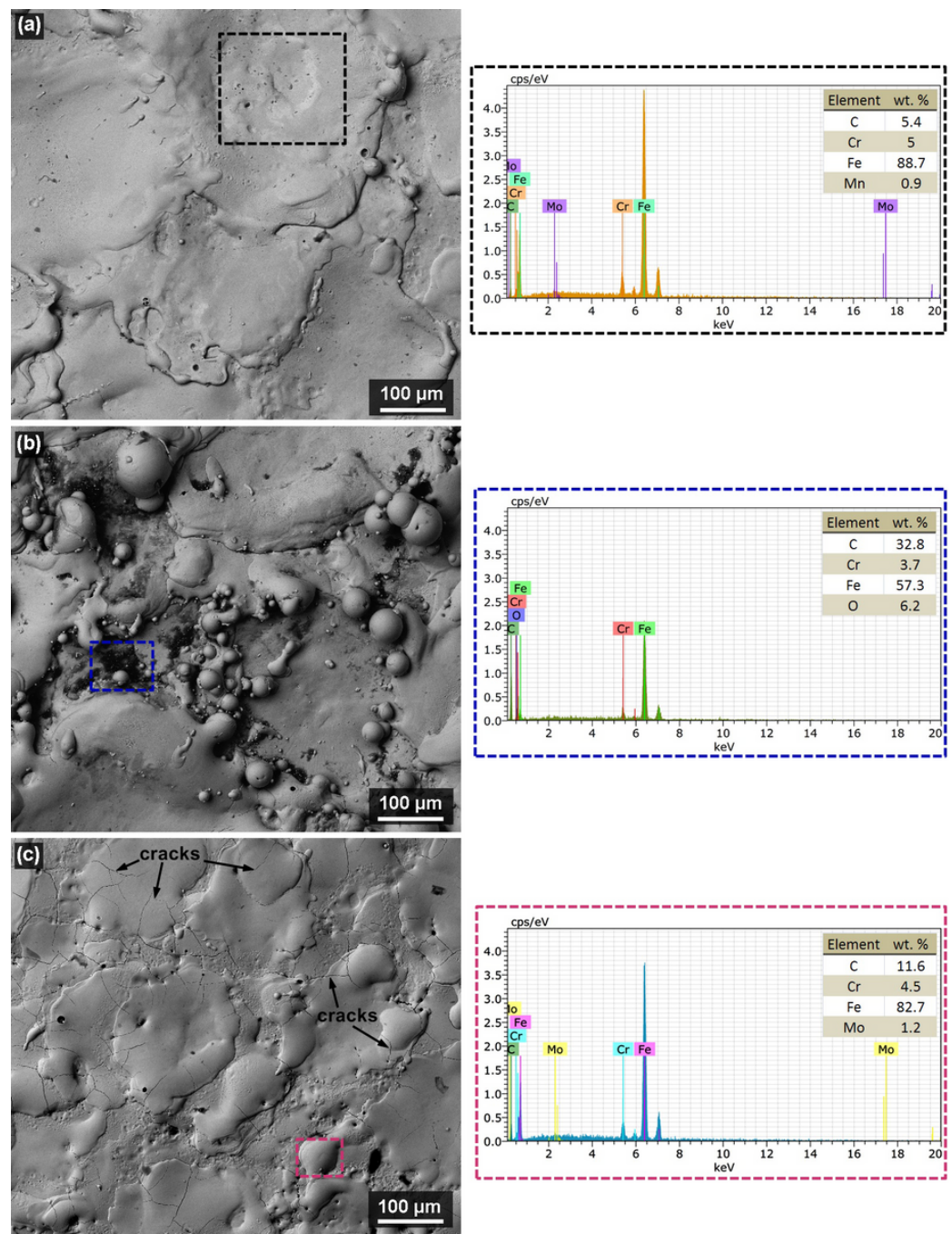

\section{Figure 6}

Surface morphology of SEM samples (BSE) including chemical composition analysis (a) Sample 50 made of 1.2343 ESR steel machined with a graphite electrode with a shape of $100 \times 100 \mathrm{~mm}$, (b) Sample 42 made of 1.2363 steel machined with a copper electrode with a shape of $10 \times 10$ mm, (c) Sample 3 made of 1.2363 steel machined with a graphite electrode with a shape of $100 \times 100 \mathrm{~mm}$. 


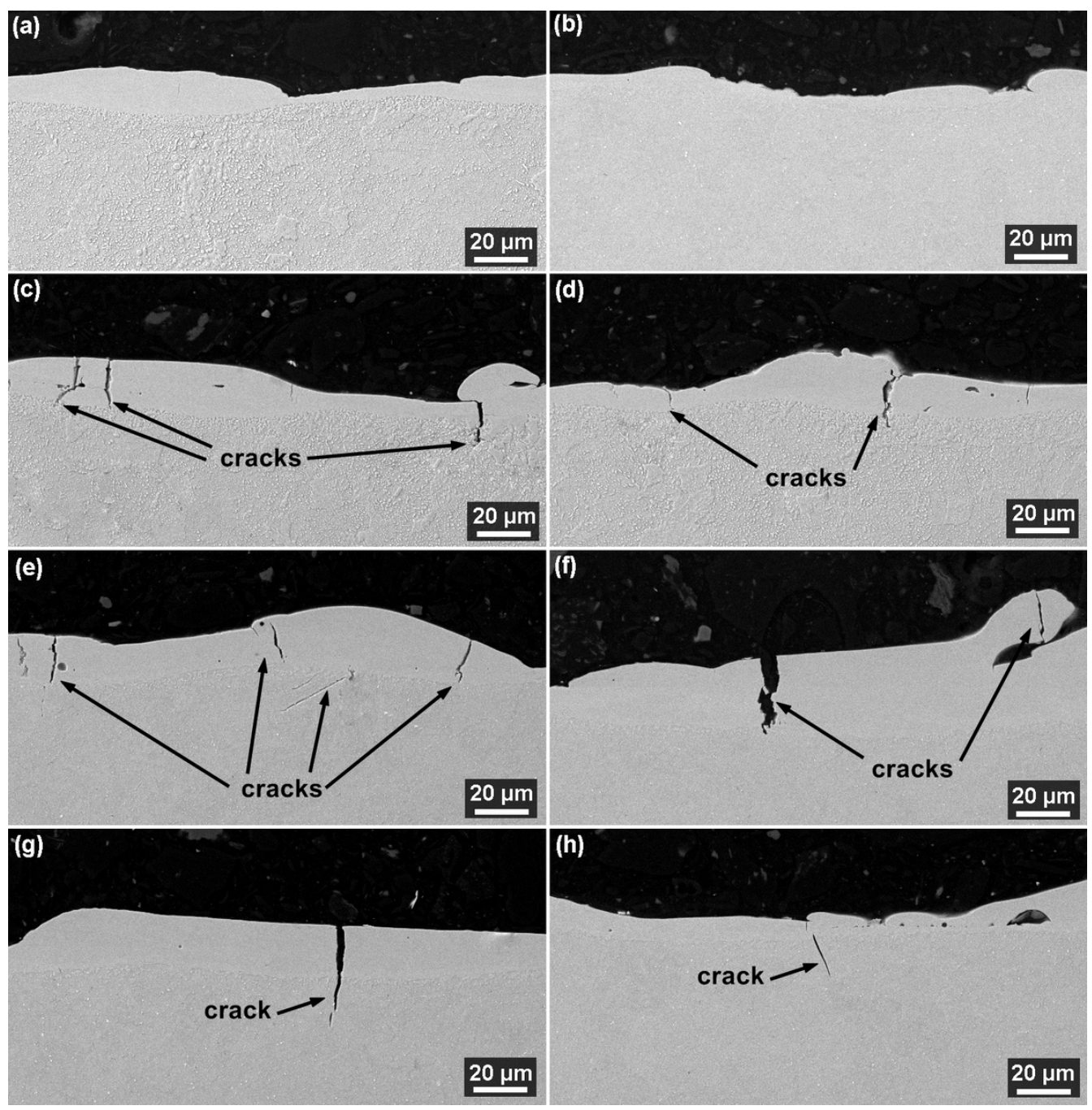

Figure 7

Cross-section showing the condition of the subsurface layer of samples and defects, SEM (BSE) (a) Sample 42 made of 1.2363 steel machined with a $10 \times 10$ mm copper electrode, (b) Sample 50 made of 1.2343ESR steel machined with a 100x100 mm graphite electrode, (c, d) Sample 3 made of 1.2363 steel machined with a graphite electrode with a shape of $100 \times 100 \mathrm{~mm}$, (e) Sample 22 made of $1.2343 \mathrm{ESR}$ steel machined with a copper electrode with a shape of $10 \times 10 \mathrm{~mm},(\mathrm{f}, \mathrm{g})$ Sample 24 made of steel 1.2343ESR machined with graphite electrode with shape 100x100 mm, (h) Sample 73 from steel $1.2343 \mathrm{ESR}$ machined with graphite electrode with shape $100 \times 100 \mathrm{~mm}$. 


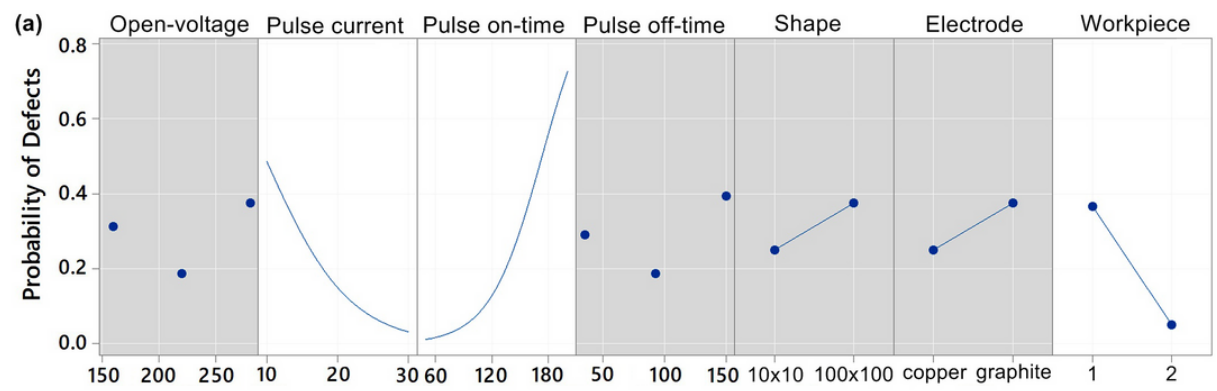

A gray background represents a term not in the model.
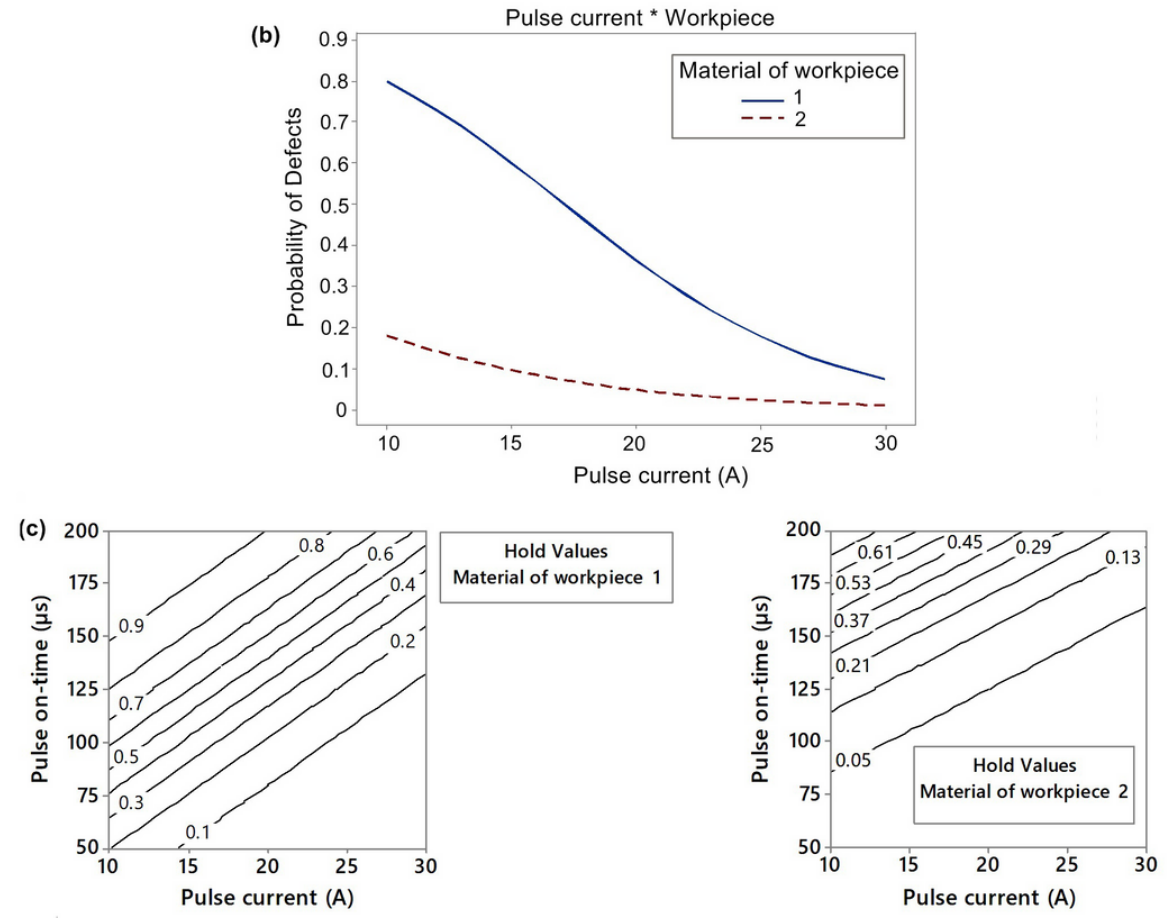

\section{Figure 8}

(a) Main Effects Plot for Probability of Defects, (b) Interaction Plot for Probability of Defects, (c) The resulting regression area describing the probability of surface defects depending on significant input factors. 


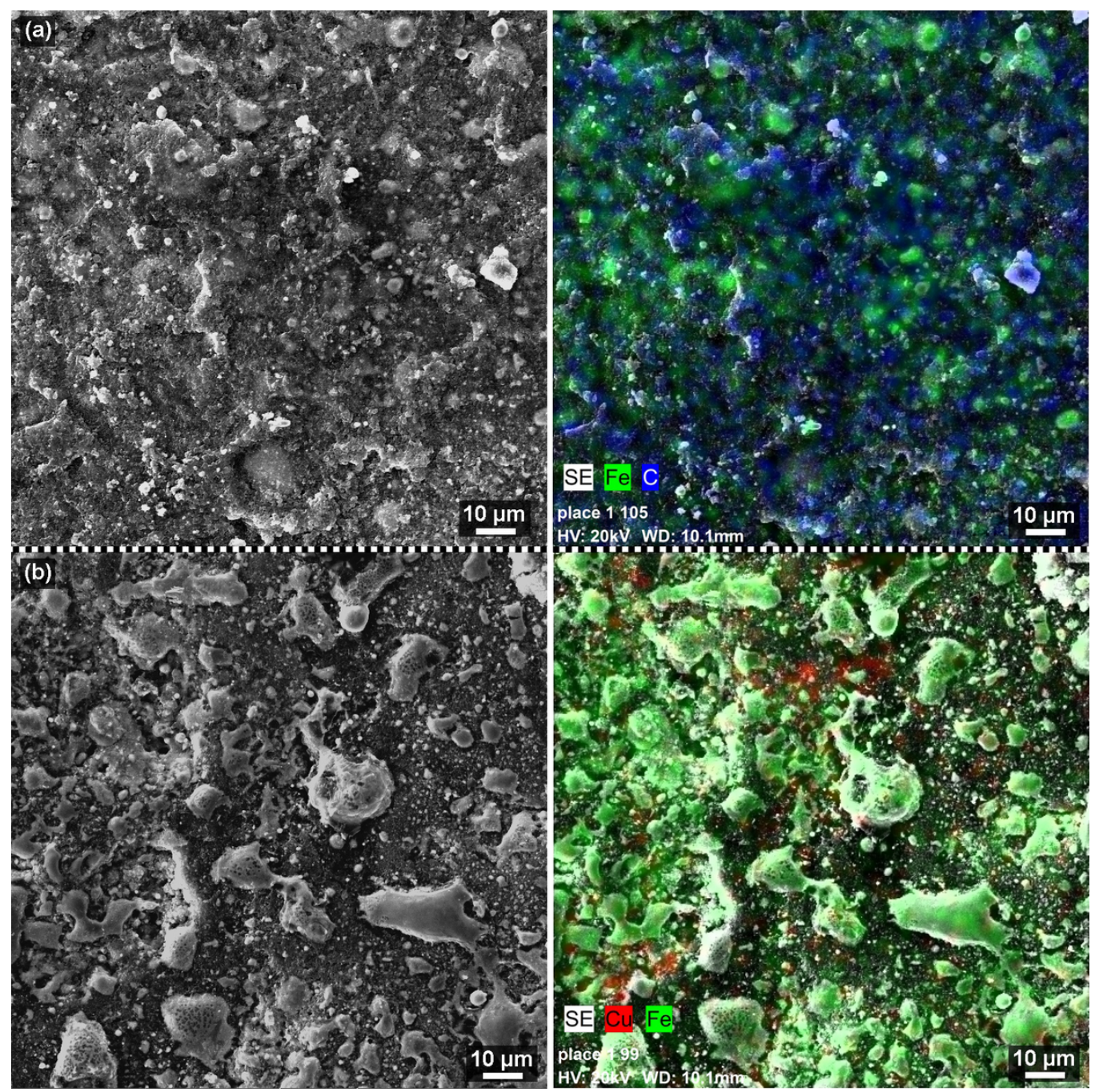

Figure 9

The surface morphology of SEM electrodes (SE) including the chemical composition analysis (a) graphite electrode $100 \times 100$ mm used in machining Sample 50 from steel 1.2343ESR, (b) copper electrode $10 \times 10 \mathrm{~mm}$ used in machining Sample 42 from steel 1.2363. 


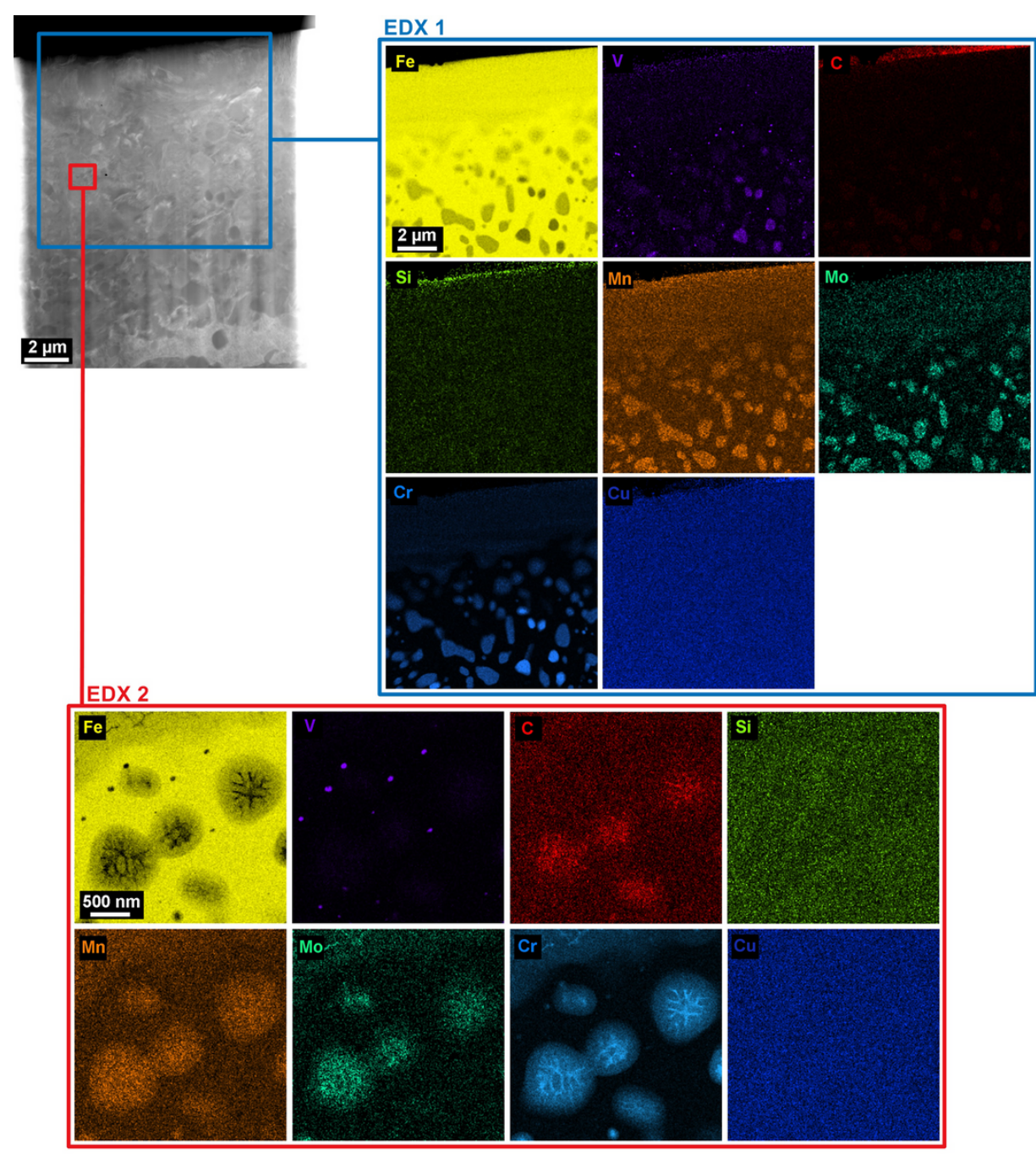

Figure 10

TEM lamella made of 1.2363 steel, including maps of the distribution of individual elements in various details. 


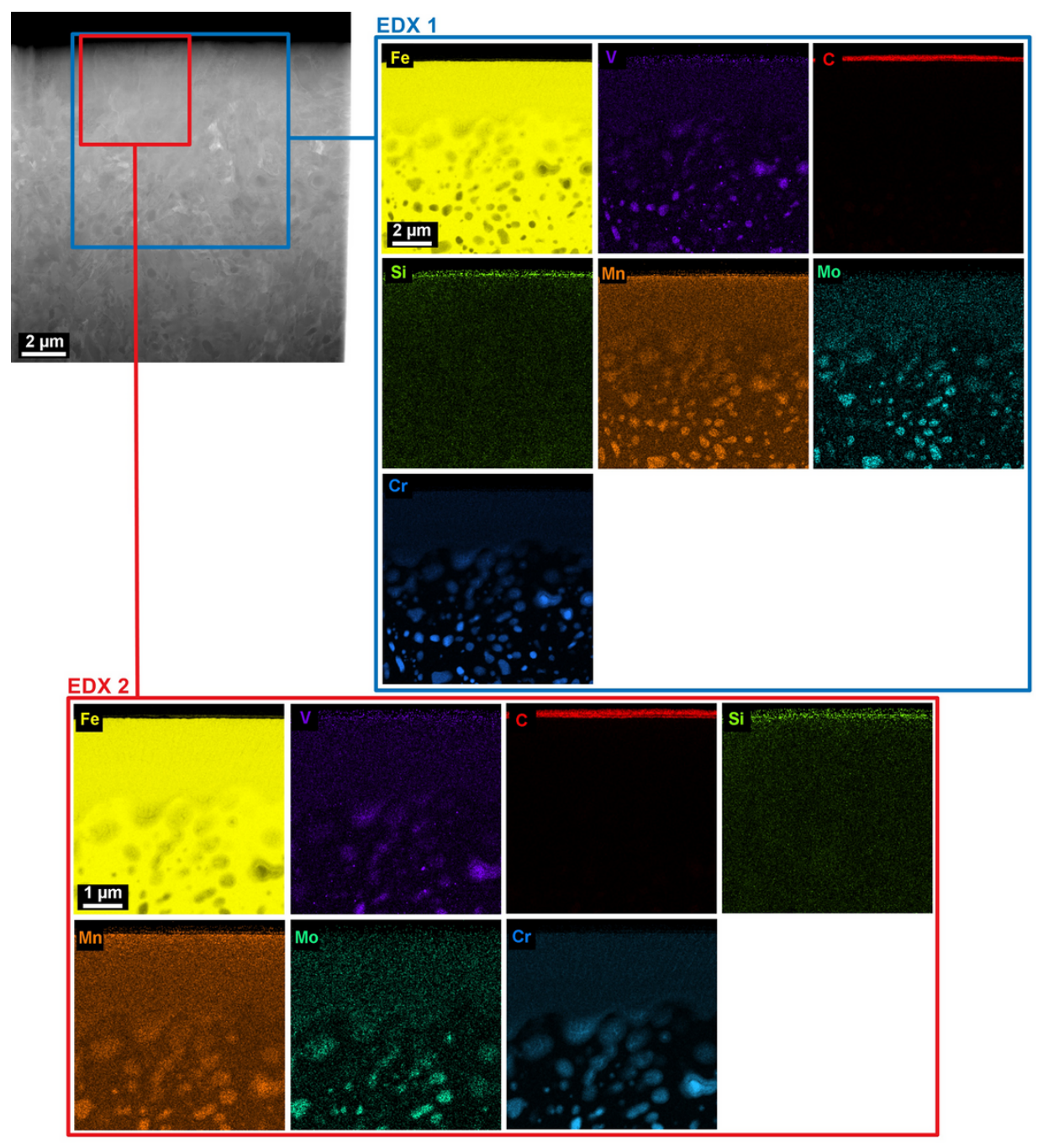

Figure 11

TEM lamella made of 1.2343ESR steel, including maps of the layout of individual elements in various details. 